\title{
Post-activation potentiation induced by concentric contractions at three speeds in humans
}

Alexander Zero, The University of Western Ontario

Supervisor: Dr. Charles L Rice, The University of Western Ontario

A thesis submitted in partial fulfillment of the requirements for the Master of Science degree in Kinesiology

(C) Alexander Zero 2021

Follow this and additional works at: https://ir.lib.uwo.ca/etd

Part of the Exercise Science Commons, and the Motor Control Commons

\section{Recommended Citation}

Zero, Alexander, "Post-activation potentiation induced by concentric contractions at three speeds in humans" (2021). Electronic Thesis and Dissertation Repository. 7726.

https://ir.lib.uwo.ca/etd/7726

This Dissertation/Thesis is brought to you for free and open access by Scholarship@Western. It has been accepted for inclusion in Electronic Thesis and Dissertation Repository by an authorized administrator of Scholarship@Western. For more information, please contact wlswadmin@uwo.ca. 


\section{Abstract}

Post-activation potentiation (PAP) is the acute enhancement of contractile properties following a short duration $(<10 \mathrm{~s})$ high intensity contraction. Compared with isometric contractions, little is known about the PAP response induced by concentric conditioning contractions (CCs) and the effect of contractile speeds. In the dorsiflexors of 10 participants, twitch responses were measured following 5s of maximal effort concentric CCs at each of 10, 20 and $50 \%$ s. Concentric PAP responses were compared to a maximal isometric voluntary contraction (MVC) matched for contraction time. Additionally, concentric CCs were compared to isometric CCs matched for mean torque, contraction area and time. The principal finding was that the PAP response following maximal concentric CCs was independent of contractile speed and, there was no difference in the PAP response between concentric CCs and an isometric MVC. Maximal contractions, regardless of contraction modality, likely produce sufficient $\mathrm{Ca}^{2+}$ to induce a full PAP response, and thus there was no difference between speeds or contraction type. Concentric CCs had significantly larger peak twitch torques than their isometric torque matches (49-58\%), and faster maximal rates of torque development at the three speeds (62-77\%). However, these responses are likely related to greater muscle activation (EMG), and not contraction modality per se. Thus, PAP responses following maximal concentric CCs are not affected by velocity and responses are not different from an isometric MVC. This indicates maximal CCs produce a full PAP response independent of contraction type (isometric vs concentric) or shortening velocity.

\section{Key words}

Isokinetic, Contractile history, Skeletal muscle, Conditioning contraction, Myosin phosphorylation 


\section{Lay Summary}

Following repetitive high force contractions muscles can experience fatigue. However, following a high force contraction of short duration $<10$ s muscle force can become enhanced for a short period $\sim 30 \mathrm{~s}-10 \mathrm{~min}$. This enhanced force response is called post-activation potentiation (PAP), and the PAP response is related to the force level of the previous contraction. PAP is a biochemical "warm-up" in which the previous contraction primes myosin, which is a key protein involved in muscle contraction. The contraction which creates this PAP response is well understood during an isometric contraction (no joint movement). However, isometric contractions have less applicability to daily dynamic movements. Thus, the purpose of the present study was to investigate the PAP response after concentric (muscle shortening) contractions at three joint speeds $(10,20$ and $50 \%$ s) and compare the response to isometric contractions. In 10 participants ( 7 males and 3 females) the PAP response was measured after isometric and concentric contractions $(10,20$ and 50\% $)$ of the ankle joint muscles on the front of the leg. Following maximal isometric (no joint movement) and maximal concentric (muscle shortening) contractions at 10, 20 and $50 \%$ s there was no difference in the PAP response. Because the force of the contraction to produce PAP is a determining factor, force between isometric and concentric contractions were matched. When matched for force, concentric contractions at all speeds produced a greater PAP response than isometric contractions. Additionally, there were no differences in the PAP response between concentric speeds. These findings show concentric contractions at slow and moderate speeds produce a similar PAP response as a maximal isometric contraction. However, when the force production was matched between contraction types (concentric and isometric) concentric contractions produced larger PAP responses regardless of the speed of contraction. 


\section{Co-Authorship statement}

Experimental data were collected and analysed by Alexander M. Zero. Alexander M. Zero and Charles L. Rice participated in interpretation of experimental data. 


\section{Acknowledgements}

Firstly, I would like to thank Dr. Allman, Dr. Belfry and Dr. Christie for taking the time to examine my thesis and providing thoughtful feedback.

I would like to thank past lab mates Dave and Kevin. Eric, Jacob and Paish thank you for always asking the tough questions, willingness to pilot projects and for making the lab a fun place to work this past year. Kalter, thank you for your friendship and for showing me the work ethic it takes to be a successful master's student. I am also grateful there was someone to talk soccer with!

Charles, thank you for taking me as a master's student. I am grateful to work with a supervisor who is as dedicated as you are to his lab and students. I consider myself lucky to learn from a mentor who I can call a friend. Without your support, commitment, and friendship this thesis would not be complete, and I would not be the person and researcher that I am today.

Lastly, I would like to thank my friends and family. Lindsey, thank you for supporting me unconditionally. To my parents, thank you for the never-ending support, for teaching me the importance of hard work and for being role models. 


\section{Table of Contents}

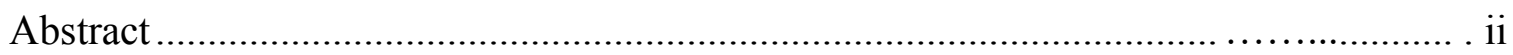

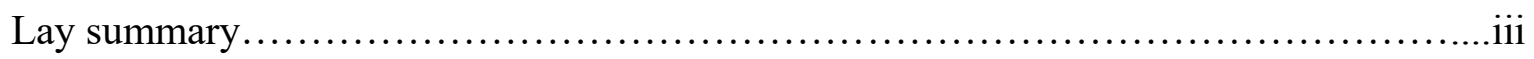

Co-Authorship Statement......................................................... iv

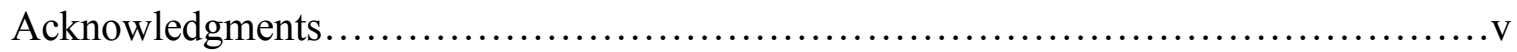

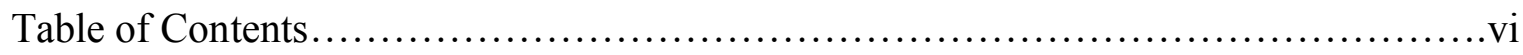

List of tables......................................................................

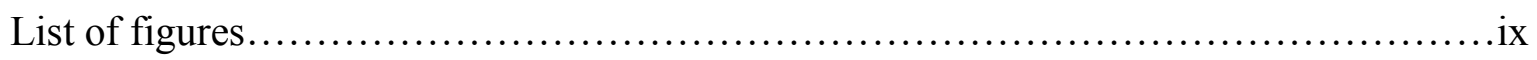

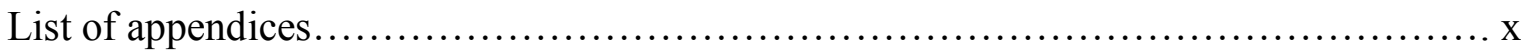

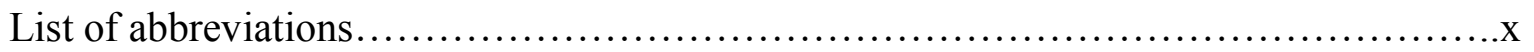

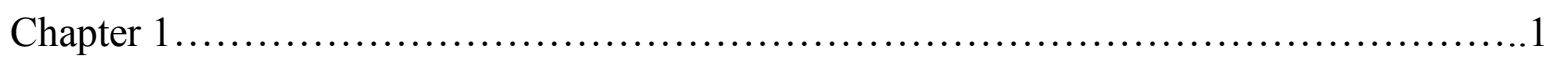

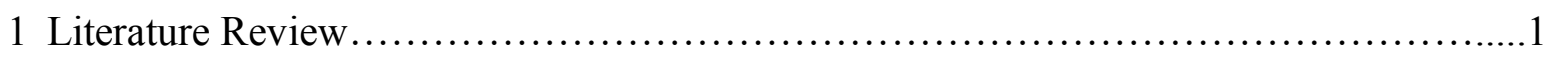

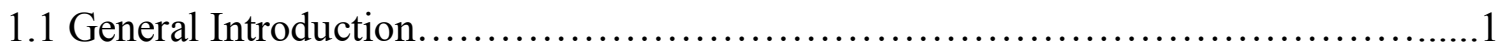

1.2 Skeletal Muscle: structural and functional hierarchy ..............................

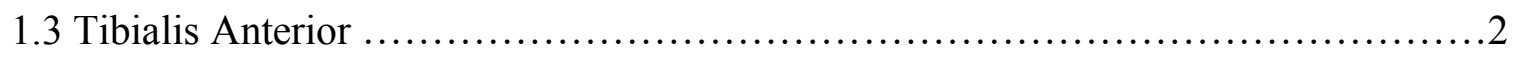

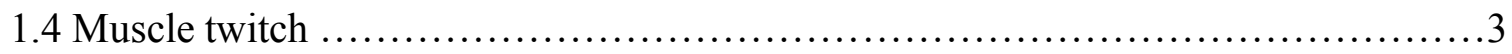

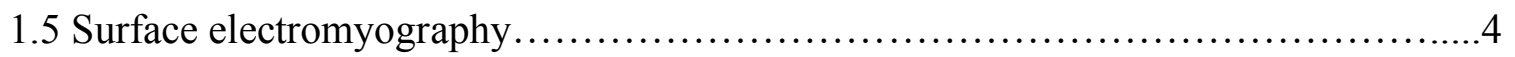

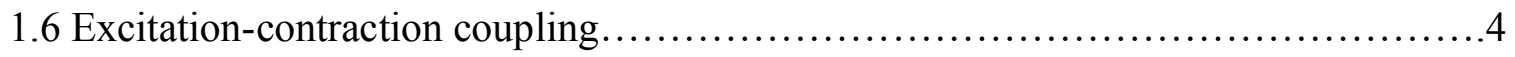

1.7 Isometric and concentric muscle contractions ...................................6

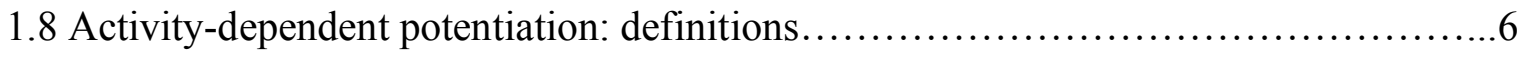

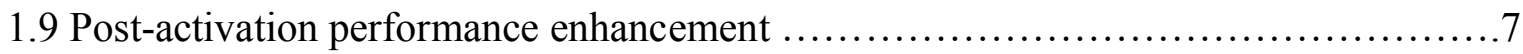

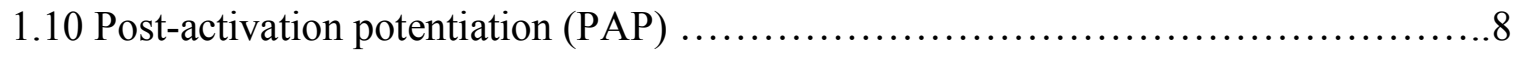

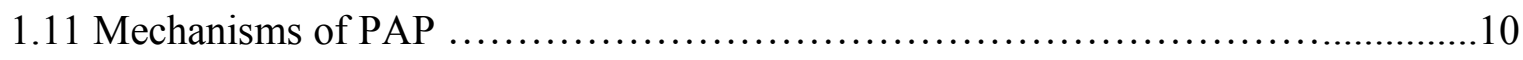

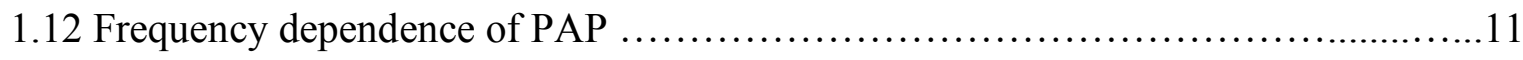

1.13 Interactions between fatigue and PAP ............................................ 
2 Post-activation potentiation induced by concentric contractions at three speeds in

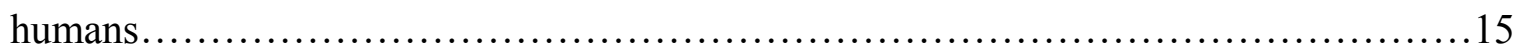

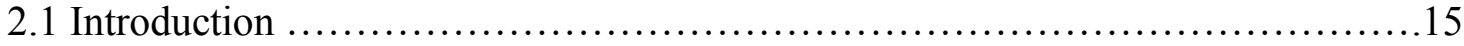

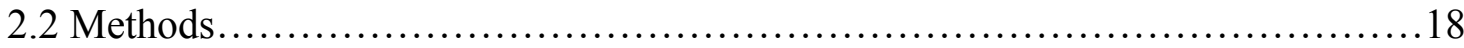

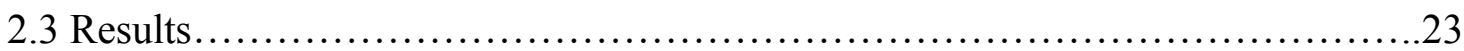

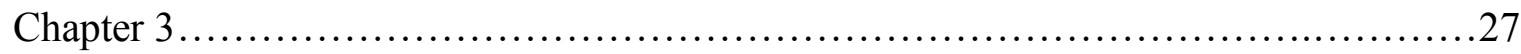

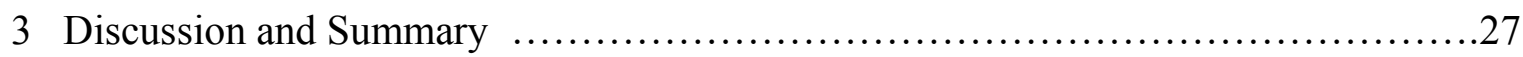

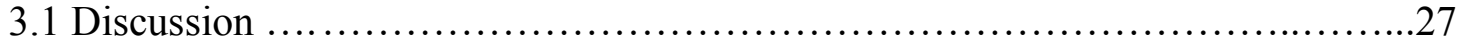

3.2 Conclusions........................................................ 31

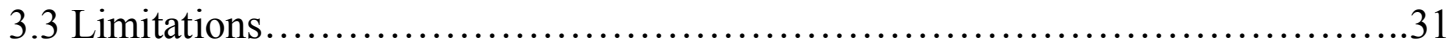

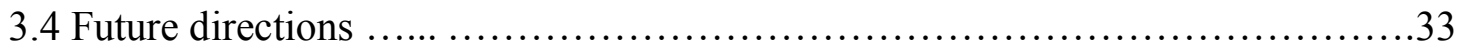

References..............................................................

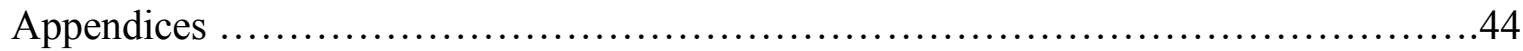

Appendix A. Ethical Approval.............................................44

Appendix B. Permissions to reprint previously published manuscript materials..........45

Curriculum Vitae $\quad$.....................................................46 


\section{List of tables}

Table 1. Voluntary and stimulated contractile measurements and surface electromyography....25 


\section{List of figures}

Figure 1. Anatomical view of tibialis anterior muscle.............................. 3

Figure 2. Example of post-activation potentiation (PAP) $\ldots \ldots \ldots \ldots \ldots \ldots \ldots \ldots \ldots \ldots \ldots$

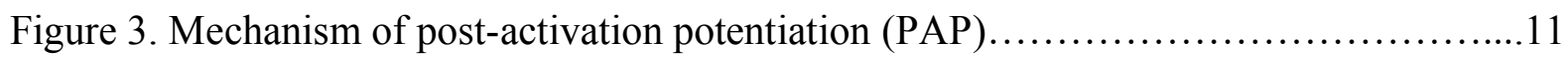

Figure 4. Sigmoidal relationship between force and $\mathrm{Ca}^{2+}$ concentrations $(\mathrm{pCa}) \ldots \ldots \ldots \ldots . . .12$

Figure 5. Example surface electromyography and kinematic data of two maximal dorsiflexion

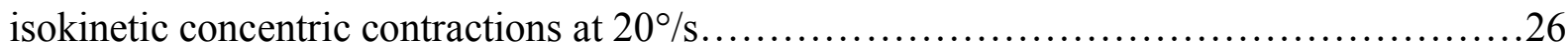

Figure 6. Example of muscle twitch responses after conditioning contractions (CC)....... 26 


\section{List of appendices}

Appendix A: Ethical approval...............................................44

Appendix B: Permissions to reprint previously published manuscript materials............45

\section{List of abbreviations}

ADP - adenosine diphosphate

ANOVA - analysis of variance

ATP - adenosine triphosphate

$\mathrm{CaM}$ - calmodulin

$\mathrm{CC}$ - conditioning contraction

ITT - interpolated twitch technique

$\mathrm{KO}$ - knock out

MHC- myosin heavy chain

MRLC - myosin regulatory light chain

MLCP - myosin light chain phosphatase

MU - motor unit

MVC - maximal voluntary contraction

$\mathrm{nm}$ - nanometers

PAP - post-activation potentiation

PAPE - post-activation performance enhancement

$\mathrm{pCa}$ - calcium concentration

$\mathrm{Pi}$ - phosphate

PLFFD - prolonged low frequency force depression

$\mathrm{Pt}$ - peak twitch torque

PTP - post-tetanic potentiation

RMS - root mean square

ROM - range of motion

RTD - rate of torque development

S1 - subfragment-1

S2 - subfragment-2

sEMG - surface electromyography

SERCA pump - sarcoplasmic reticulum $\mathrm{Ca}^{2+}$ ATPase pump 
skMLCK - skeletal myosin-light chain kinase

SR - sarcoplasmic reticulum

$\mathrm{T}$ - tubules - transverse tubules

TA - tibialis anterior

VA - voluntary activation

WT - wildtype 


\section{Chapter 1}

\section{Literature Review}

\subsection{General Introduction}

The contractile properties of skeletal muscle can be acutely impaired or enhanced depending on its contractile history. Following fatiguing contractions contractile properties can become impaired demonstrating contractile weakness and slowing. However, following a short high intensity contraction, contractile properties may become enhanced demonstrating faster contractile properties with a greater force generating capacity. This enhanced muscular phenomenon is referred to as activity-dependent potentiation. The principles underlying activitydependent potentiation are well studied primarily during isometric contractions, whereas, other acute high intensity contraction modalities to induce this response have received much less exploration. Isometric contractions (no joint movement) have less applicability to daily dynamic movements and thus it is important to understand whether this inherent activity-dependent property is induced following dynamic contractions (joint movement) and what other factors are involved in modifying activity-dependent potentiation in dynamic movements as compared with isometric actions (Baudry \& Duchateau 2004).

\subsection{Skeletal muscle: structural and functional hierarchy}

Human skeletal muscle is a highly organized structure comprised of thousands of multinucleated muscle fibres. Within each muscle fibre are cylindrical myofibril units arranged in parallel and these contain longitudinal contractile building blocks called sarcomeres which are boarded by $\mathrm{Z}$ discs. Sarcomeres are the basic element of muscle contraction, comprised of mostly actin and myosin contractile filaments (Rassier 2010). The force production of a whole muscle is proportional to the number of sarcomeres acting in parallel, and conversely, velocity is proportional to the number of sarcomeres acting in series (Gans \& Bock 1965; Gans 1982; Sacks \& Roy 1982). Therefore, the functional capability of a whole muscle is influenced by its structure. For example, muscles designed for high velocity actions such as orbicularis oris surrounding the eye have fibres that are very long and aligned along the axis of force generation (Johnson et al. 1973; Powell et al. 1984), whereas, the vasti muscles of the thigh are designed for 
high force production and have fibres in a pennate arrangement fixed to the relative axis of force generation. This pennation arrangement increases the number of sarcomeres in parallel (Johnson et al. 1973; Wickiewicz et al. 1983).

Human skeletal muscle is a heterogeneous tissue. Specifically, muscle fibres are comprised of a diverse array of fast and slow types and subtypes. Fibre types can be delineated according to differences in both structural and functional properties. There are many isoforms of myosin (Pette \& Staron 2000), which is a fundamental contractile protein for muscle contraction. Thus, the most common method for classifying fibre type is by myosin profiles, specifically myosin heavy chain (MHC) isoforms as this is where a majority of functional differences exist between myosin profiles (Weiss et al. 1999a). The three main fibre types are: MHC type I, type IIA and type IIX. However, fibre types should not be strictly classified and should be expressed as a continuum because of the existence of hybrid fibres (Pette \& Staron 2000, Heckman \& Enoka 2012). Hybrid fibres is a term used to describe a muscle fibre which displays a co-expression of MHC isoforms. When a fibre displays a single MHC isoform the fibre is deemed 'pure', but hybrid fibre types are delineated based on the predominate MHC isoform it displays (Pette \& Staron 2000). This organized continuum matches the phenotypic properties well with the fibres' functional contractile properties (Barany 1967; Close 1967). Within the fibre type groupings (Type I, IIA, IIX), type I are considered 'slow' fibres because the contractile properties are slower, they produce less force but are also the most fatigue resistant. These characteristics grade with the fibre type continuum, such that Type IIX display the fastest contractile properties, the greatest force production and are the least fatigue resistant (Harriage et al. 1996). Furthermore, the ATP used per unit of force, and maximal shortening velocity is highest in type IIX and lowest in type I (Bottinelli et al. 1994b; Larsson \& Moss 1993). Thus, fibre typing should be regarded as a continuum in human skeletal muscle.

\subsection{Tibialis Anterior}

The tibialis anterior (TA) is the largest muscle of the anterior leg (Figure. 1). The TA is a bipennate, superficial muscle predominantly composed of Type I muscle fibres ( 75\%) (Johnson et al. 1973). It is the primary dorsiflexor (Marsh et al. 1981), and also functions to invert the foot making the TA functionally important for gait and balance (Hardin \& Devendra 2020, Azam et 
al. 2020). The TA is innervated by the deep fibular nerve, which can be palpated lateral and posterior to the head of the fibula. The superficial location of this nerve makes it accessible for percutaneous peripheral nerve stimulation to assess involuntary muscle properties of the TA. The TA therefore is a common muscle of study because it is the biggest contributor to dorsiflexion ( $\sim 40-60 \%)$ and the muscle can easily be stimulated due to peripheral nerve accessibility (Fukunaga et al. 1996; Marsh et al. 1981).

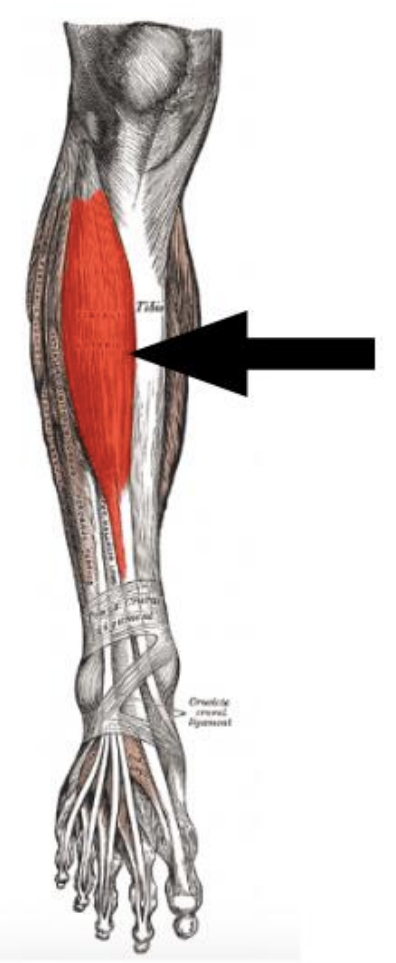

Figure 1. Anatomical view of tibialis anterior muscle. (Adapted from https://www.physiopedia.com/File:Tibialis_anterior_close.png)

\subsection{Muscle twitch}

A muscle twitch is the transient force response produced by a single low frequency $(1 \mathrm{~Hz})$ maximal electrical stimulus. Stimulation may be done over the muscle or the nerve which innervates the muscle of interest. The twitch response encompasses the entire excitationcontraction coupling process, but due to active-state processes represents a sub-maximal unit of contractile activation. An evoked twitch response allows for the control of input the muscle receives in relation to the contractile output. Maintaining the same input (frequency and stimulus 
intensity) allows for the assessment of muscle contractile properties pre and post interventions. Various influences of activation histories, such as muscle fatigue may alter aspects of the twitch response. The evoked twitch response may become altered by a change in its magnitude (force), time course (duration), or both.

\subsection{Surface electromyography}

Surface electromyography (sEMG) is a non-invasive technique used to record and assess global myoelectrical activity. Recording of sEMG is done by placing electrodes on the surface of the skin directly over the muscle of interest. Myoelectrical activity is propagated by axons and muscle fibre conduction and represents the activation of motor units (MU) as functional contractile units. The MU is defined as the lower motor neuron and the muscle fibres' it innervates (Lindell and Sherrington 1925). MUs regulate contractile output by recruitment/derecruitment and/or adjusting firing rates (rate coding) of already recruited MUs (Heckman \& Enoka 2012). Signals recorded by sEMG cannot distinguish between these two mechanisms (recruitment and rate coding) but represent an approximation of neural drive to the muscle (De Luca 1997). Because sEMG is non-invasive it is an attractive technique to measure and understand myoelectrical signals. However, there are many factors which can affect sEMG interpretation such as electrode shift, interelectrode distance and subcutaneous tissue properties (Farina 2006). With limitations in mind, sEMG provides a useful tool to measure myoelectrical activity and is commonly used in exercise studies (Farina 2006).

\subsection{Excitation-contraction coupling}

Excitation-contraction coupling describes the communication between electrical activity at the muscle fibres sarcolemma and the sarcoplasmic reticulum release of $\mathrm{Ca}^{2+}$ ultimately producing a muscle contraction (Sandow 1952). The first step in excitation-contraction coupling is the depolarization of the sarcolemma membrane via neuromuscular transmission. Fast $\mathrm{Na}^{+}$channels open once the membrane potential reaches threshold and the action potential is propagated along the sarcolemma down the transverse tubules (T-tubules). The T-tubules contain both $\mathrm{Na}^{+}$and $\mathrm{K}^{+}$ channels in addition to $\mathrm{Ca}^{2+}$ channels called dihydropyridine receptors. Dihydropyridine receptors are densely packed within the T-tubules and function as voltage sensors detecting the 
action potential membrane depolarization. Ryanodine receptors are the $\mathrm{Ca}^{2+}$ channels of the sarcoplasmic reticulum (SR). The detection of depolarization via dihydropyridine receptors triggers ryanodine receptors to open, subsequently releasing $\mathrm{Ca}^{2+}$ from the terminal cisternae of the SR. This release increases $\mathrm{Ca}^{2+}$ within the myoplasm. Troponin $\mathrm{C}$ is a regulatory protein attached to the thin filament, the free $\mathrm{Ca}^{2+}$ in the myoplasm binds with Troponin $\mathrm{C}$. The binding of $\mathrm{Ca}^{2+}$ to Troponin $\mathrm{C}$ exposes the actin myosin binding cites by physical displacement of tropomyosin away from these sites (Bers 2002; Gordon et al. 2001). Each troponin C will remain away from these sites only if $\mathrm{Ca}^{2+}$ occupies the given troponin $\mathrm{C}$. Tropomyosin movement exposes seven actin monomers, thus these seven sites are now open for cross-bridge development (Gordon et al. 2001). Once myosin-binding sites are exposed, and sufficient ATP is present, myosin can bind to actin, and this forms a cross-bridge. Specifically, the globular end of myosin referred to as the $\mathrm{S} 1$ region, has multiple hinged segments which can bend and change its conformation to pull on actin (Hynes et al. 1987; Spudich 2001). The 'tail', or S2 region of myosin is slimmer, exhibits flexibility, rotates and works collectively with the S1 region to create contraction (Spudich 2001). The S2 region tethers the S1 region to the thick filament, remaining in place as the actin filament moves $\sim 10 \mathrm{~nm}$ (nanometers) (Spudich 2001). This movement by the S1 region is called the 'power stroke'. The energy for the power stroke is by the hydrolysis of $\mathrm{ATP}$ as ADP and Pi are released during this motion. After contraction a new ATP molecule is needed to remove the $\mathrm{S} 1$ region from actin. Without this ATP, myosin would remain bound with actin (Lorand 1953). After myosin removal this process can repeat, and is referred to as crossbridge cycling. When a cross-bridge is formed myosin pulls on actin and the sarcomeres shorten by bringing the Z-discs closer together. The summation of multiple shortening sarcomeres amplifies the response subsequently shortening the whole muscle and transfers forces along the tendon to the bone producing joint rotation. Although ATP supplies the energy for contraction, $\mathrm{Ca}^{2+}$ is an important regulator. Without sufficient $\mathrm{Ca}^{2+}$ tropomyosin will block the myosin-actin binding sites (Lehman et al. 1994). Therefore, although sufficient ATP may be present low myoplasmic $\mathrm{Ca}^{2+}$ can terminate myosin actin interaction by $\mathrm{Ca}^{2+}$ uptake into the $\mathrm{SR}$. The membrane pump responsible for this uptake is called sarcoplasmic reticulum $\mathrm{Ca}^{2+}$ ATPase (SERCA) (Bers 1997; Bers 2002). Thus, even if sufficient ATP is present, a reduction in $\mathrm{Ca}^{2+}$ concentration to a resting level (via SERCA pumps) will exponentially decrease the number of active force generating cross-bridges. 


\subsection{Isometric and concentric muscle contractions}

Isometric contractions, or fixed end contractions, are defined as an active muscle contraction in which the joint does not move in response to muscle activation. In contrast, a concentric contraction is an active muscle contraction in which the joint is allowed to move due to active shortening of muscle fibres and therefore the whole muscle. Although joint angle remains stable during isometric contractions, cross-bridge cycling and active internal muscle fibre shortening are occurring to produce force (Hill 1938; Katz 1939; Muthu et al. 2008), but this shortening is less than concentric due to the restraint of the fixed joint angle.

The sliding filament and cross-bridge theories of muscle contraction explain that force production in isometric contractions is dependent on both the number of formed cross-bridges and the sarcomere length which alters myofilament overlap (Blix 1894; Huxley 1957). Therefore, force production is lower when isometric contractions are performed at muscle lengths which position actin-myosin overlap into a sub-optimal force generating state. Thus, it is well described that isometric force production is dependent on the joint angle (muscle fibre length) which ultimately alters cross-bridge formation (Gorden et al. 1966a). During a concentric contraction the joint angle is actively changing with a concurrent alteration is actin-myosin overlap. As muscle length shortens (concentric movement) the number of active cross-bridges are fewer (Piazzei et al. 2007) in addition to sub-optimal actin-myosin overlap, thus resulting in less force production during concentric movement when compared to isometric. Additionally, during concentric contractions there is an increase of $\mathrm{Ca}^{2+}$ within the myoplasm (Allen \& Kurihara 1982; Ashley \& Moisecu 1975; Stephenson \& Wendt 1984) likely because there is less $\mathrm{Ca}^{2+}$ bound to troponin C (Stephenson \& Wendt 1984) as more cross-bridges are within a nonforce generating state (Piazzesi et al. 2007).

\subsection{Activity-dependent potentiation: definitions}

There are several terms which are commonly used as synonyms to describe the enhanced contractile response for a given activation following previous muscle activation (MacIntosh 2010; Smith and MacIntosh 2021). The broadest term to describe this muscle response is activity dependent potentiation. Within this general term there are three distinctions: staircase, post- 
tetanic potentiation, and post-activation potentiation. To uncover and quantify any of these enhancements an artificially evoked contractile response with the same stimulation parameters is needed pre and post muscle activation. These terms cannot be used to describe this muscle phenomenon unless a submaximal evoked contraction is measured pre and post muscle activation. This evoked contraction is used to quantify and detect changes in activation.

Staircase describes the progressive enhancement of the muscle twitch response during repeated stimulation at low frequencies from rest (MacIntosh 2010). The frequency to induce staircase is muscle, species and temperature dependent (MacIntosh 2010). Staircase is not commonly used in human models to study activity-dependent potentiation. Post-tetanic potentiation (PTP) is the enhanced contractile response for a given submaximal activation following an artificially evoked tetanic contraction (Brown and Von Euler 1938; Guttman et al. 1937). PTP is commonly used when voluntary activation is impossible, such as reduced muscle preparations, or to segmentally study an intact neuromuscular system. There are benefits for using PTP, however the process to potentiate the muscle is non-physiological. For example, in humans maximal evoked peripheral nerve stimulation causes a constant synchronous activation of all motor units, which does not occur under voluntary control (Heckman \& Enoka 2012). Post-activation potentiation (PAP) is the enhanced contractile response for a given sub-maximal activation following voluntary muscle activation (Burke et al. 1976; Sale 2002). Thus, the study of PAP may be more

functionally relevant as it involves voluntary muscle activation to potentiate the muscle as opposed to involuntary stimulation (PTP). PAP is the most common form of activity dependent potentiation used in human models of study (Blazevich \& Babault 2019), however, PTP can also be beneficial in human models of study to evaluate muscle responses without the confounding variables related to voluntary control (Smith et al. 2020).

\subsection{Post-activation performance enhancement (PAPE)}

Within the last 20 years many published studies have misused the terms associated with activity dependent potentiation. For these terms to be used correctly, specifically PTP and PAP, there must be the evaluation of submaximal contractile properties before and after muscle activation using the same stimulation parameters (Smith \& MacIntosh 2021). This controlled assessment of activation allows for the measurement of muscle contractile properties. Without a pre and post 
contraction assessment PTP and PAP are not applicable terms. Although PAP has been used and defined as the improvement in voluntary performance (such as power) following prior activation without any pre or post contractile activation assessments (Boullosa et al. 2020), this is not correct terminology. Indeed, PAP may improve voluntary performance, but post-activity enhancement can occur regardless of the presence of PAP. These enhancements following activation not directly attributed to PAP or PTP, may be due to features broadly categorized as "warm-up". PAP may occur as a response to "warm-up" only if the effects overlap in a similar timeframe, and contraction effort is of high intensity. However, this time relationship is often unknown as potentiation is not assessed (with evoked contractions) in these studies (Till \& Cooke 2009). Recently, the term post-activation performance enhancement (PAPE) has been introduced for these scenarios. PAPE is a term to describe other factors unrelated to PAP but which have associations with previous contractions (e.g., muscle temperature, water content, blood flow) that can alter voluntary muscle control, and in some cases improve voluntary performance (Blazevich \& Babault 2019; Boullosa et al. 2020; Cuenca-Fernandez et al. 2017; Zimmermann et al. 2019). Factors related to PAPE are unrelated to direct mechanisms of PAP because PAP is transient ( $\sim 30 \mathrm{~s}-10 \mathrm{~min})$ and factors related to PAPE are often long-lasting (Baudry \& Duchateau 2004; Blazevich \& Babault 2019; Hamada et al. 2003; MacIntosh and Gardiner 1987; Seitz et al. 2015; Vandervoort et al. 1983). PAPE is the correct term to describe the effect of previous contractions on voluntary performance when confirmation of enhanced contractile elements is not present and is more long lasting. Although the term PAP has been well defined historically (Blazevich \& Babault 2019; Burke et al. 1976), recent studies have defined PAP incorrectly (Boullosa et al. 2020) leading to studies describing results related to PAP when indeed PAP was not properly assessed or quantified. Despite the definition of PAPE being well described there remain misconceptions regarding the mechanisms and definition of PAP as opposed to PAPE (Boullosa et al. 2020).

\subsection{Post-activation potentiation (PAP)}

Skeletal muscle contractility is highly dependent on previous contractile history, which can either enhance or impair subsequent contractions. Post-activation potentiation (PAP) refers to the acute contractile enhancement following a voluntary (5-10s) muscular contraction at a high intensity ( $>75 \%$ of maximum) (Vandervoort et al. 1983) (Figure 2). Following this high- 
intensity conditioning contraction (CC) the force response can be facilitated $\sim 200 \%$ for the same input stimulus (Baudry \& Duchateau 2004). This enhanced force response is measured by an evoked contraction (muscle twitch) and is graded with the intensity of the CC (Vandervoort et al. 1983). However, a high-intensity CC for a long duration $(\sim>10 \mathrm{~s})$ can impair the subsequent response due to fatiguing influences (Rassier \& MacIntosh 2000). Muscle fatigue, defined by a decrement in force output (Gandevia 2001) is also facilitated by high-intensity contractions thus there is a balance between PAP and muscle fatigue (Vandervoort et al. 1983).

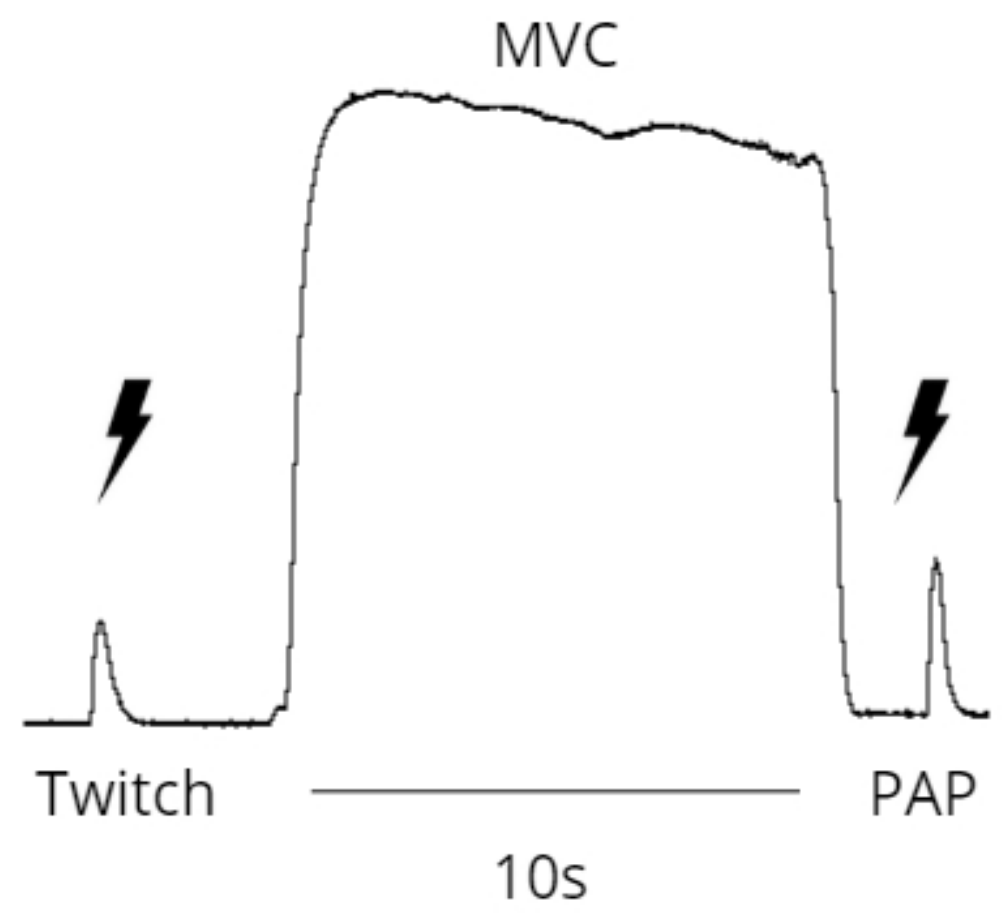

Figure 2. Example of post-activation potentiation (PAP). Maximal evoked muscle twitch before and after a short duration maximal voluntary contraction (MVC).

A muscle twitch is used to quantify PAP and twitch potentiation describes the transient enhancement (torque and/or rate of torque development) of the muscle twitch response following a CC (Sale 2002). The PAP response is immediately maximal after the CC and the PAP response follows an exponential decay to baseline levels within $\sim 30$ s to $\sim 10$ minutes (Vandervoort et al. 1983; Hamada et al. 2003; Baudry \& Duchateau 2004; MacIntosh \& Gardiner 1987; Seitz et al. 2015). This process of PAP decay is therefore measured by intermittent twitch responses post CC. Both the potentiation capability and time course of PAP decay is affected by fibre type 
composition. Specifically, Type II fibres have a greater potentiation capacity as they contain 3.5 times more skeletal myosin-light chain kinase (skMLCK) than Type I fibres, and there is positive relationship with twitch potentiation and myosin light chain phosphorylation (Houston \& Grange 1991). Additionally, the oxidative capability of the muscle fiber is negatively correlated with twitch potentiation (Moore \& Stull 1984; Houston \& Grange 1991). Therefore, it is well established Type II muscle fibres have a greater PAP response than Type I fibres (Ryder et al. 2007).

\subsection{Mechanisms of PAP}

The mechanisms for PAP have been thoroughly investigated and it is understood that the primary mechanism of PAP is myosin regulatory light chain (MRLC) phosphorylation in relation with improved $\mathrm{Ca}^{2+}$ sensitivity (Grange et al. 1993; Manning \& Stull 1979; Persechini et al. 1985; Sweeney 1993; Vandenboom et al. 1993), visually depicted in Figure 3. During muscle contraction the sarcoplasmic reticulum releases $\mathrm{Ca}^{2+}$ and increases calmodulin $(\mathrm{CaM})$ concentrations, $\mathrm{Ca}^{2+}$ is bound to CaM and activities skMLCK (Manning and Stull 1982). The interaction of CaM and skMLCK (Blumenthal \& Stull 1980) phosphorylates the RLC of the myosin molecule (Levine et al. 1991). Once phosphorylated, myosin head orientation shifts steepening the angle in relation to the thin filament (Levine et al. 1996). The number of forcegenerating cross bridge interactions increases due to the new orientation of myosin reducing the distance between actin binding sites (Levine et al. 1996) and additionally increases cross bridge attachment rate (Sweeney \& Stull 1990). The improved cross-bridge interaction subsequently improves $\mathrm{Ca}^{2+}$ sensitivity. The dissipation of PAP is by the dephosphorylation of MRLCs and is governed by a myosin light chain phosphatase (MLCP) (Sweeney et al. 1993). Reuptake of $\mathrm{Ca}^{2+}$ dissociates CaM and skMLCK which triggers this phosphatase to remove the phosphate from the MRLCs returning myosin orientation to its resting state (Sweeney et al. 1993). 
Figure 3. Mechanism of post-activation potentiation (PAP); taken from Blazevich \& Babault 2019 Frontiers in Physiology openly distributed under the terms of the Creative Commons Attribution Licence.

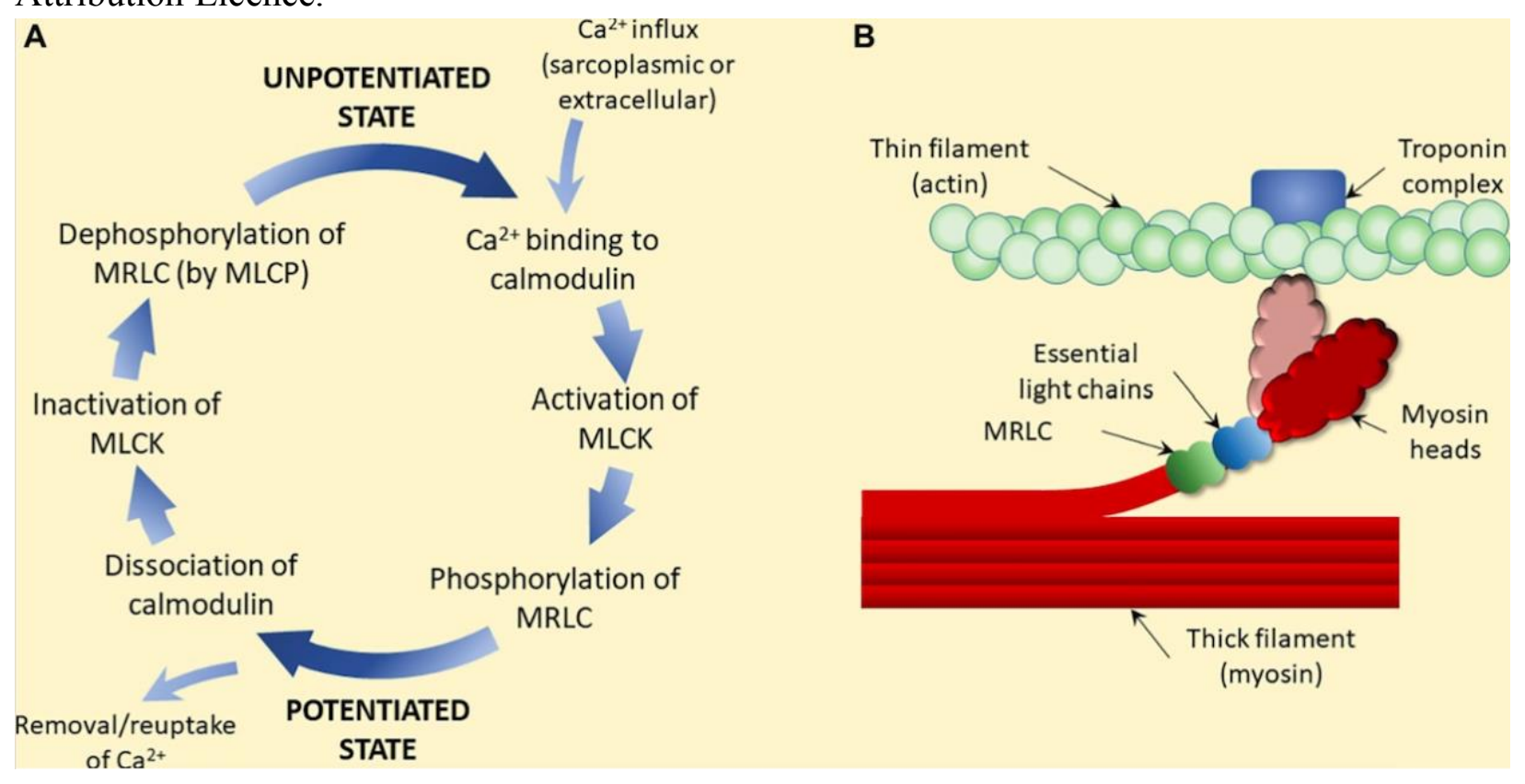

\subsection{Frequency dependence of PAP}

The effects of PAP are most apparent at low myoplasmic levels of $\mathrm{Ca}^{2+}$, such as low frequencies of excitation or submaximal contraction intensities. As phosphorylation-mediated modification to myosin structure (PAP) improves $\mathrm{Ca}^{2+}$ sensitivity varying myoplasmic $\mathrm{Ca}^{2+}$ states will have differing response to this mechanism (Figure 4). The greatest effects of improved $\mathrm{Ca}^{2+}$ sensitivity are seen during contractile states with low levels of $\mathrm{Ca}^{2+}$, such as with twitch responses. At low myoplasmic $\mathrm{Ca}^{2+}$ (low or submaximal frequencies of excitation) there is a large effect of increased $\mathrm{Ca}^{2+}$ sensitivity during PAP. At high levels of myoplasmic $\mathrm{Ca}^{2+}$ (ie., at higher maximal frequencies of activation) the effect of improved $\mathrm{Ca}^{2+}$ sensitivity gradually becomes diminished as the sarcoplasm has become saturated with $\mathrm{Ca}^{2+}$ (Sweeney et al. 1993). Therefore, PAP demonstrates a ceiling effect and does not improve maximal voluntary force output, or contractile states during maximal frequency stimulation (Sale 2002; Smith et al. 2011; Persechini et al. 1985; Sweeney \& Stull 1986). 


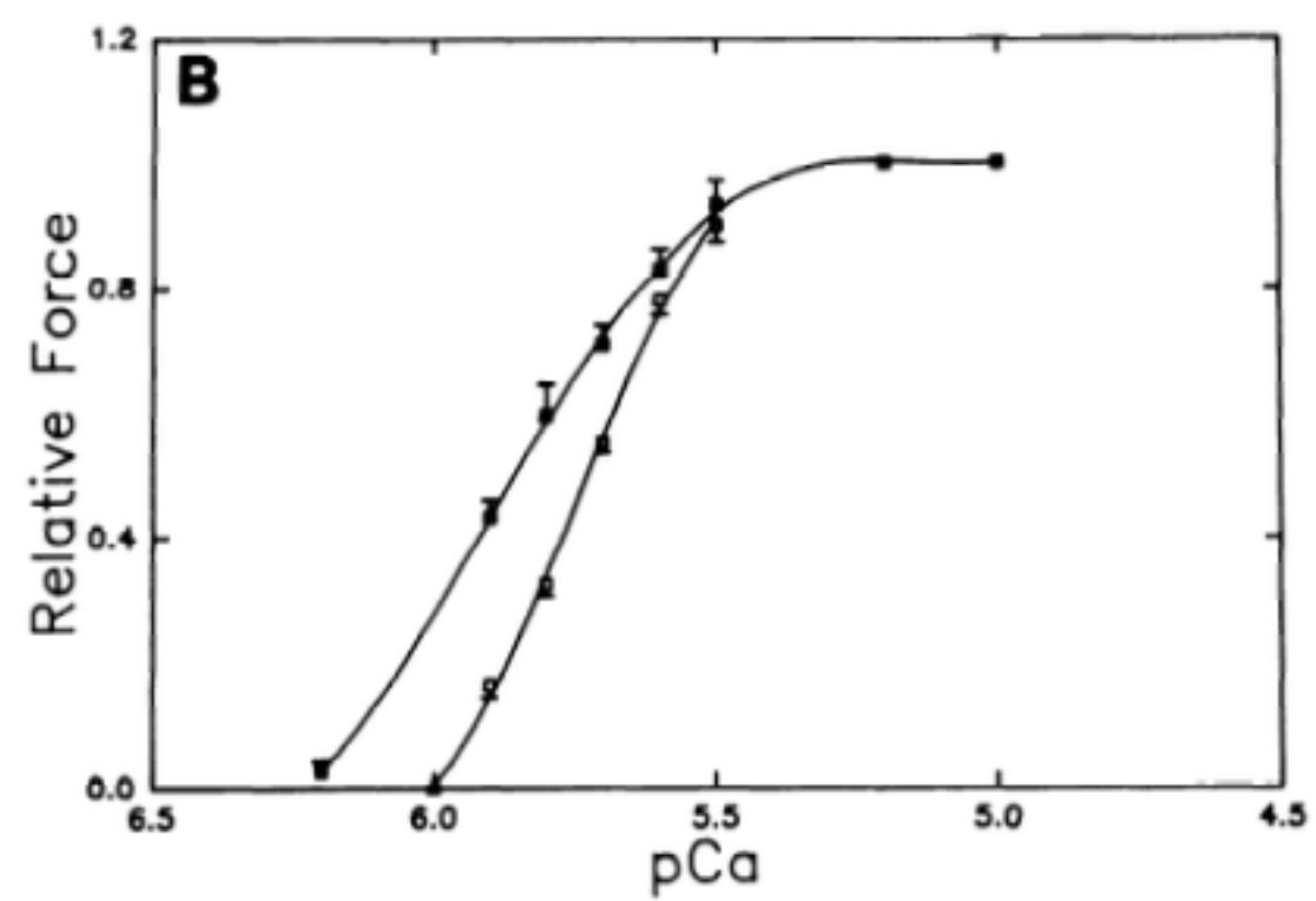

Figure 4. Sigmoidal relationship between force and $\mathrm{Ca}^{2+}$ concentrations $(\mathrm{pCa})(-\log 10)$. ForcepCa relationship before (open squares with bottom line) and after phosphorylation of myosin regulatory light chains (closed squares with top line). Left-ward shift of force-pCa curve during potentiation, indicating greater potentiation of force at submaximal $\mathrm{pCa}$ levels. No change in force-pCa curve during $\mathrm{Ca}^{2+}$ saturation. Used with permission (Sweeney 1993).

Type II fibres demonstrate the greatest PAP capability, however, the mechanisms of PAP have the greatest effect during submaximal contraction intensities where smaller Type I motor units (and fibres) predominate (Henneman \& Mendell 1981). Although Type I fibres have an impaired PAP capability opposed to Type II it has been shown human muscles predominately composed of Type I fibres can demonstrate a significant PAP response (Vandervoort et al. 1983; Xenofondos et al. 2015). Additionally, the greatest effects of PAP are seen when Type I motor units and fibres predominate (low-levels of excitation). Thus, although the PAP capability is lower than Type II fibres, Type I fibres see the greatest augmentation during PAP. Although Type I fibres can experience PAP it is paradoxical that Type II fibres, which have the greatest capability for PAP (Houston \& Grange 1991; Moore \& Stull 1984) are predominantly active during higher force contractions, where the mechanisms for PAP have less effect. As such, it has been proposed the greater PAP response in Type II fibres is a "waste" (Sale 2002). However, human muscle fibres display mixed fibre types, and thus fibre typing should be considered as a 
continuum (Heckman \& Enoka 2012; Pette \& Staron 2000). Thus the difference in PAP capability between "Type I" and "Type II" fibres in humans is likely not as substantial compared to varying species used in reduced preparations where foundational knowledge on potentiation was demonstrated (Blumenthal \& Stull 1980; Houston \& Grange 1991; Persechini et al. 1985; Sweeney et al. 1993; Vandenboom et al. 1993).

\subsection{Interactions between fatigue and PAP}

A brief $(<10$ s) high-intensity contraction $\sim>75 \%$ maximal contraction will induce a PAP response, however, a sustained ( $>10 \mathrm{sec})$ high-intensity contraction will induce muscle fatigue, which is defined as a decrement in force output (Gandevia 2001; Vandervoort et al. 1983). Both history-dependant force altering responses result from previous muscular activation and because of this it is difficult to distinguish the effect of one from the other. Additionally, in certain circumstances these processes can co-exist (Rassier \& Macintosh 2000). Rankin et al. 1988 intermittently assessed the twitch (low-frequency) and tetanic (100hz, high frequency) force responses during fatiguing tetanic contractions ( $40 \mathrm{hz}$ for 6 minutes). During these measurements the twitch was enhanced and the tetanic contraction was depressed $(\sim 70 \%)$ relative to prefatigued measures. Using a similar protocol Jami et al. 1983 found similar results directly following evoked fatiguing contractions. However, Jami et al. 1983 followed the force responses (twitch and tetanic) after a period of recovery ( $\sim 4$ hours). Following this recovery tetanic force was minimally depressed, as opposed to evoked twitches which displayed a greater depressed force response which was not present directly following the stimulation protocol. Because the twitch was depressed following recovery prolonged low frequency force depression (PLFFD) was indicated. Thus, another important feature of this relationship between fatigue and potentiation is that potentiation dissipates within minutes (MacIntosh \& Gardiner 1987; Moore \& Stull 1984,), whereas muscle fatigue and more specifically PLFFD can continue for hours (Edwards et al 1977). This relationship of PLFFD and potentiation also has been demonstrated in humans (Fowles \& Green 2003). Thus, it is clear that muscle fatigue and potentiation can co-exist, however, the physiological relevance of this interaction is not completely understood. Two commonly proposed cellular mechanisms for muscle fatigue are a reduced $\mathrm{Ca}^{2+}$ release and/or decreased $\mathrm{Ca}^{2+}$ sensitivity (Bruton et al. 2008; Cheng et al. 2015; Ortenblad et al. 2000; Westerblad et al. 1991). Since the phosphorylation of MRLC enhances $\mathrm{Ca}^{2+}$ sensitivity 
(potentiation) it has been suggested that a function of potentiation may be to counteract the process of muscle fatigue (Green \& Jones 1989; MacIntosh \& Rassier 2002; Rankin et al. 1988). Gittings et al. 2011 tested the effects of skMLCK gene ablation on the muscle fatigability in mice. They demonstrated that skMLCK knock out (KO) mice had a reduced capability to potentiate compared with the wildtype (WT) mice. During intermittent fatiguing tetanic $(150 \mathrm{~Hz})$ contractions twitch force in the WT mice was significantly higher than in the KO mice until tetanic force dropped $\sim 60 \%$. Tetanic force decline was similar between both WT and KO mice. Therefore, inhibiting MRLC phosphorylation (KO mice) accelerated the fatigue related decline in twitch force (low frequency) but not tetanic force (high frequency). Thus, potentiation may mitigate fatigue related force decline at low frequencies. However, it is unknown how inhibiting MRLC phosphorylation through skMLCK gene ablation would affect submaximal force production with frequencies above the twitch response $(1 \mathrm{~Hz})$.

\subsection{Purpose and Hypothesis}

The CC to induce PAP has been well-studied using isometric contractions. It is well-understood that to produce a large PAP response there is an optimal relationship between intensity (\% maximum) and contraction time (Fukutani et al. 2012; Vandervoort et al. 1983). However, the type of CC (isometric vs concentric) has received little attention (Baudry \& Duchateau 2004). Furthermore, it is unknown how the effect of concentric CC speeds (velocity) will affect the PAP response. Thus, the purpose of this study was to characterize the effect of concentric CCs at three speeds $(10,20$ and $50 \%$ s) on the PAP response measured by evoked twitches. Concentric CCs at each speed were compared to isometric CCs matched for the same mean torque output, total contraction area and contraction time. Additionally, concentric CCs were compared to isometric MVCs with matched contraction times. During concentric contractions there are greater myoplasmic $\mathrm{Ca}^{2+}$ levels (Ashley \& Moisecu 1975; Lab et al. 1984; Stephenson \& Wendt 1984) compared to isometric, thus I hypothesize concentric contractions at all speeds will produce a greater PAP response than an isometric MVC matched for time. Additionally, the PAP response will grade with contraction speed such that the fastest concentric $\mathrm{CC}\left(50^{\circ} / \mathrm{s}\right)$ will produce the largest PAP response, and when matched for torque, total contraction area and contraction time concentric CCs will produce a larger PAP response than isometric contractions. 


\section{Chapter 2}

\section{Post-activation potentiation induced by concentric contractions at three speeds in humans}

\subsection{Introduction}

Contractile properties of skeletal muscle are history-dependent and activation history can either enhance or impair subsequent contractions. Post-activation potentiation (PAP) is the acute contractile enhancement immediately following a voluntary induced brief (5-10s) muscular contraction at high intensity ( >75\% of maximum) (Sale 2002; Vandervoort et al. 1983). The contraction to induce PAP is termed the conditioning contraction (CC). The PAP response is assessed by comparing the response of an electrically induced maximal twitch immediately following a $\mathrm{CC}$ to one induced prior to the $\mathrm{CC}$ at the same maximal stimulation intensity. From the perspective of the active state in a muscle the twitch is a submaximal response (versus a tetanus) and potentiation is defined as the transient enhancement of both twitch peak torque and maximal rate of torque development (RTD) following a CC (Sale 2002). This transient muscular facilitation can increase twitch torque upwards of $200 \%$ (Baudry \& Duchateau 2004; Smith et al. 2011) and following an isometric CC is maximal immediately and follows an exponential decay to baseline levels within $\sim 30$ s to $\sim 10$ minutes depending on the muscle and degree of PAP induced (Baudry \& Duchateau 2004; Hamada et al. 2003; MacIntosh \& Gardiner 1987; Seitz et al. 2015; Vandervoort et al. 1983).

The two factors considered in inducing a large degree of PAP have been contraction intensity and duration (Fukutani et al. 2012; Fukutani et al. 2014; Vandervoort et al. 1983), whereas the influence of the type of contraction (isometric vs concentric) has received very limited exploration (Baudry \& Duchateau 2004). This, despite the necessity for skeletal muscle to undergo dynamic stretch and shortening cycles to create joint movements. In one prior study in humans it was reported that a maximal effort concentric CC produced a similar PAP response as an isometric maximal voluntary contraction (MVC) (Baudry \& Duchateau 2004). However, the concentric contraction was performed at a very slow joint rotation of $5 \% \mathrm{~s}$ in the dorsiflexors compared with a potential ankle joint rotation speed of $\sim 175 \%$ s even when loaded at $20 \% \mathrm{MVC}$

A version of this chapter has been submitted to Experimental Physiology. Zero, A.M \& Rice, C.L. (2021) Post-activation induced by concentric contractions at thee speeds in humans. 
(McNeil \& Rice 2007). The slow joint speed of $5 \%$ s is almost isometric and the effects of more functionally relevant joint rotations during faster CCs on PAP are not known.

The phosphorylation of myosin regulatory light chains (PAP) is a $\mathrm{Ca}^{2+}$ dependent process which causes modification to myosin structure and improves $\mathrm{Ca}^{2+}$ sensitivity of the contractile apparatus (Grange et al. 1993; Manning et al., 1979; Pereschini et al. 1985; Sweeney et al. 1993; Vandenboom et al. 1993). However, it is unknown how this process is altered during concentric $\mathrm{CCs}$ of moderate contractile speed. Concentric contractions have differing $\mathrm{Ca}^{2+}$ (Allen \& Kurihara 1982; Ashley \& Moisecu 1975; Housmans et al. 1983; Lab et al. 1984; Stephenson \& Wendt 1984) and cross-bridge kinetics (Piazzesi et al. 2007) when compared to isometric contractions. Specifically, during muscle shortening there is an increase of $\mathrm{Ca}^{2+}$ within the myoplasm (Ashley \& Moisecu 1975; Housmans et al. 1983; Stephenson \& Wendt 1984). Concentric contractions, especially at higher speeds, are accompanied by increased cross-bridge detachment rates, resulting in more cross-bridges within a non-force-generating state (Piazzesi et al. 2007). Sarcoplasmic reticulum (SR) $\mathrm{Ca}^{2+}$ release is independent of muscle length (Balnave $\&$ Allen 1996; Fabiato \& Fabiato 1975b; Frank \& Winegard 1976; Hui \& Gilly 1979; Yoshioka 1982) and thus concentric and isometric contractions produce the same $\mathrm{Ca}^{2+}$ release for the same input stimulus. Because there are less force-generating cross-bridges with concentric movement (Piazzesi et al. 2007) there is likely less $\mathrm{Ca}^{2+}$ bound to troponin $\mathrm{C}$ which may explain the increased myoplasmic $\mathrm{Ca}^{2+}$ levels (Housmans et al. 1983; Lab et al. 1984; Stephenson \& Wendt 1984). Furthermore, concentric movement within an in vivo model may provide additional $\mathrm{Ca}^{2+}$ release from the SR due to higher activation frequencies with concentric compared to isometric contractions (Cowling et al. 2016; Harwood et al. 2011), with a concurrent increase in myoplasmic $\mathrm{Ca}^{2+}$ due to the length-dependent decrease in $\mathrm{Ca}^{2+}$ affinity to troponin $\mathrm{C}$ (Stephenson \& Wendt 1984).

Because fatigue and PAP can coexist (Rassier \& MacIntosh 2000) the optimal contraction intensity and duration for producing a large amount of PAP while minimizing fatigue has been well-explored for isometric CCs (Fukutani et al. 2012; Fukutani et al. 2014; Vandervoort et al. 1983). However, during more functional (dynamic) movements the relative 
effects of contraction intensity and duration on inducing PAP is unknown. Additionally, the influence of variables exclusive to dynamic tasks such as contraction speed are not well understood in how they affect the PAP response. Thus, the purpose of this study was to characterize the effect of maximal concentric CCs at three speeds $\left(10,20\right.$ and $\left.50^{\circ} / \mathrm{s}\right)$ on the PAP response measured by twitch potentiation. Concentric CCs at each speed were compared to isometric MVCs with matched contraction times. Additionally, concentric CCs were compared to isometric CCs matched for the same mean torque output, total contraction area and contraction time. We hypothesized that concentric CCs at all speeds will provide a larger PAP response than an isometric MVC matched for time. Additionally, the PAP response will grade with contraction speed such that the fastest concentric $\mathrm{CC}(50 \%)$ will produce the largest PAP response, and when matched for torque, total contraction area and contraction time concentric CCs will produce a larger PAP response than isometric contractions. 


\subsection{Methods}

Participants

Eight males and 3 females $(23.6 \pm 2.8$ years old, $178 \pm 6.8 \mathrm{~cm}$ and $72 \pm 12.8 \mathrm{~kg})$ volunteered for this study. Research ethics for the study was approved by the local university research ethics board. Participants were required to provide oral and written consent before any testing was performed. Exclusion criteria included any neuromuscular or metabolic diseases.

Experimental set-up:

Dynamometer

Participants were seated upright in a dynamometer (Cybex HUMAC NORM; CSMI Medical Solutions, Stoughton, MA). Their left leg and ankle were fixed within an adaptor arm with the left ankle positioned at $115^{\circ}\left(25^{\circ}\right.$ plantar flexion) while hip angle was attained at $110^{\circ}$ and knee joint at $130^{\circ}$. Two adjustable non-elastic nylon straps and a stiff plastic clamp were placed over the dorsum of the foot to minimize extraneous movements securing the foot to the dynamometer. The lateral malleolus of the left ankle was aligned with the rotational axis of the dynamometer. Non-elastic shoulder and waist straps were used to minimize extraneous torso movements. Torque, velocity and position signals were recorded from the dynamometer, and converted from analog to digital (Power 1401, Cambridge Electronic Design) and sampled each at $500 \mathrm{~Hz}$ (Spike2, Cambridge Electronic Design, Cambridge, UK). Visual feedback of torque, velocity and position change was provided in real time from a monitor placed $\sim 1 \mathrm{~m}$ in front of the participant, and strong verbal encouragement was provided for all voluntary contraction tasks.

\section{Surface electromyography (sEMG)}

A bipolar surface electrode (GE Healthcare, resting ECG electrodes) arrangement was placed on the tibialis anterior and the soleus of the left leg. For the tibialis anterior, one electrode was placed over the muscle belly mid-way along the length of the muscle and a second placed $2 \mathrm{~cm}$ distally. For the plantar flexors (coactivation), one electrode was placed over the soleus $2 \mathrm{~cm}$ distal and $2 \mathrm{~cm}$ lateral to the inferior portion of the medial gastrocnemius and the second placed 
$2 \mathrm{~cm}$ distal. Both bipolar arrangements shared a common ground electrode on the lateral malleolus of the left ankle. Electrode signals were pre-amplified (100x), filtered between $5 \mathrm{~Hz}$ and $5 \mathrm{kHz}$ and sampled at 2500hz (Spike2, Cambridge Electronic Design).

\section{Electrical stimulation}

The common fibular nerve was used to elicit muscle twitch responses of the dorsiflexors with a stimulator (Model DS7AH; Digmiter, Welwyn Garden City, UK). A surface electrode (GE Healthcare, resting ECG electrodes) was placed directly over the fibular nerve (inferior and posterior to the head of the fibula) with the second electrode placed over the muscle belly of the tibialis anterior $\sim 3 \mathrm{~cm}$ proximal to the $\mathrm{sEMG}$ electrode. For stimulation, a square wave pulse duration of 200 microseconds was delivered at 400V. Stimulation intensity ranged between 60$170 \mathrm{~mA}$. Current intensity was adjusted until muscle twitch torque amplitude showed no further increase, despite an increase in current, at which point the current was increased $20 \%$ to a supramaximal level.

\section{Concentric contractions}

With the dynamometer placed in the isokinetic mode, participants were tasked with producing maximal effort concentric contractions at three speeds $\left(10,20\right.$ and $\left.50^{\circ} / \mathrm{s}\right)$ over a $50^{\circ}$ range of motion (ROM) of the ankle joint. Ankle angle at the onset of contraction was $115^{\circ}$ of plantar flexion and end of ROM was $165^{\circ}$ dorsiflexion. For all contractions participants were instructed to relax once the ROM was complete and to allow the dynamometer to passively return at $70^{\circ} / \mathrm{s}$ to an ankle angle of $115^{\circ}$. All concentric contraction sets were matched for contraction time $(5 \mathrm{~s})$. Thus contraction repetitions varied among the three speeds such that 1 repetition was required at $10^{\circ} / \mathrm{s}$ over the $50^{\circ} \mathrm{ROM}$, with 2 and 5 repetitions, required respectively at $20 \% \mathrm{~s}$ and $50 \%$ s. Participants were instructed to contract with maximal effort throughout the entire ROM.

\section{Protocol:}

Day 1: Familiarization 
Familiarization included producing maximal isometric (dorsiflexion and plantar flexion) contractions (MVC), concentric contractions (dorsiflexion) and electrical nerve stimulation. At an ankle angle of $115^{\circ}$, participants produced 2-4 dorsiflexion MVCs with 3-5 minute rest periods between contractions and 2-3 plantar flexion MVCs with similar periods of rest between contractions.

The dynamometer was subsequently placed in isokinetic mode. Because dynamic movement causes architectural changes to the muscle-tendon complex which may therefore increase or decrease the twitch response, participants ankle's were moved passively through the $\mathrm{ROM}\left(50^{\circ}\right)$ at each speed $\left(10,20\right.$, and $\left.50^{\circ} / \mathrm{s}\right)$ for the associated number of repetitions $(1,2,5)$. Twitch torque was measured before and after each passive contraction modality with $\sim 3$ minutes separating each trial to assess potential changes. Subsequently, participants practiced producing maximal concentric contractions at each speed $(10,20$ and 50\% $)$. Each contraction speed was performed 2-4 times (for the respective number of repetitions at each speed). Participants rested 5-10 minutes between contraction sets. The mean torque output in the last set of each concentric contraction speed was measured and used on Day 2 to match isometric contractions to the same torque output as the concentric contractions.

\section{Day 2: Experimental procedure}

Once supramaximal dorsiflexion twitch torque was achieved, voluntary activation (VA) of the dorsiflexors was assessed using the interpolated twitch technique (ITT) (Todd et al., 2004). Before contraction onset ( 2s) a single stimulus was given, and subsequently during a dorsiflexion isometric MVC a superimposed stimulation was delivered during the plateau portion of the contraction and an additional stimulation within $\sim 2 \mathrm{~s}$ after completion of the MVC while the muscle was at rest. Five minutes rest was given after the MVC. A plantar flexion MVC ( $\sim 5 \mathrm{~s})$ then was recorded to normalize the antagonist (soleus) sEMG recorded during the dorsiflexion contractions. One repetition of each concentric contraction speed (10, 20 and $50 \%$ s) was done to assess torque reliability between days, with 5 minutes of rest provided between repetitions. If mean torque was within $\sim 3 \%$ of the first testing session (Day 1) data were used for the isometric matched contractions. 
Fibular nerve stimulation producing a maximal dorsiflexion twitch was done before each conditioning contraction and subsequently done at 1, 3, 5, 10, 30, 45, 60, 90 and 120s after the contraction to follow any changes in the twitch properties during a period of recovery. A minimum of 5 minutes was given as rest between each contraction and to allow for any potentiation response to dissipate. Contractions were not re-initiated until twitch torque returned to baseline levels. Firstly, an isometric dorsiflexion MVC (5s) was done and potentiation was assessed. Next, three separate $5 \mathrm{~s}$ dorsiflexion isometric contractions were preformed, in random order, matching the mean torque output of each concentric contraction set $\left(10,20\right.$ and $\left.50^{\circ} / \mathrm{s}\right)$ from the familiarization session. Isometric matched contractions were termed $10 \mathrm{~m}, 20 \mathrm{~m}$ and $50 \mathrm{~m}$. Subsequently, the dynamometer was placed in isokinetic mode and participants produced maximal effort concentric contractions, in random order, at each speed (10, 20 and 50\% $)$ over a 50 degrees $\mathrm{ROM}$ (from $115^{\circ}$ of plantar flexion to $165^{\circ}$ dorsiflexion). One repetition for $10^{\circ} / \mathrm{s}, 2$ repetitions for $20 \%$ s and 5 repetitions for $50 \%$ s so that each contraction set contained 5 s of active contraction. For multiple repetitions at 20 and $50 \%$ s subsequent repetitions were initiated immediately after the return of the lever arm $\left(70^{\circ} / \mathrm{s}\right)$ to the contraction start angle of $115^{\circ}$. To assess PAP, fibular nerve stimulation producing a maximal dorsiflexion twitch was done before each contraction set and repeated at 1, 3, 5, 10, 30, 45, 60, 90 and 120s after each set to follow the twitch potentiation decay. A minimum of 5 minutes of rest was given between each contraction set and to allow for any potentiation response to dissipate. Contractions were not initiated until twitch torque returned to baseline levels.

\section{Data analyses}

Mean torque values and total contraction area (area under torque line) during the concentric and isometric contractions were measured during the entire ROM (concentric) or contraction plateau (isometric). Muscle twitch contractile properties of peak torque $(\mathrm{Nm})$ and maximal rate of torque development (RTD) in Nm/ms were calculated. Bipolar sEMG was used to assess tibialis anterior and soleus activity assessed by root-mean-squared (RMS) amplitude measured during the entire active ROM (concentric) or plateau contraction epoch (isometric). The soleus RMS sEMG value obtained during an isometric plantar flexion MVC was used to normalize RMS sEMG for all dorsiflexion contractions to assess coactivation of the plantar flexors. All 
dorsiflexion contractions (isometric and concentric) were normalized to tibialis anterior RMS sEMG amplitude during a dorsiflexion isometric MVC. VA was calculated as previously described (Todd et al., 2004).

\section{Statistical analysis}

Analysis was performed in R (version 3.4.3). Data distribution was assessed using the ShapiroWilk test of normality. A repeated measures two-way ANOVA was used to compare mean torque output and total contraction area across all contraction types (concentric and isometric) and intensity. Intensity refers to velocities for concentric contractions and each isometric grouping (10m, 20m, 50m and MVC). A repeated two-way ANOVA was used to compare peak twitch torque, and maximal RTD across all contraction types (concentric and isometric) and intensity. Soleus sEMG data in 3 participants was removed from statistical analysis due to technical problems during data collection. A repeated measures two-way ANOVA was used to compare normalized RMS sEMG during dorsiflexion for the tibialis anterior and soleus across all contraction types (concentric and isometric) and intensity. A paired two-tailed t-test was used to compare baseline peak twitch torque to peak twitch torque following passive joint movement at each speed $(10,20$ and 50\% $)$. A Tukey Post Hoc test was used to assess where differences exist in the ANOVA tests with a significant effect. All data are reported as mean and standard deviation. Alpha was set at 0.05 . 


\subsection{Results}

\section{Contractile measurements}

Contractile measurements are presented in Table 1 and kinematic exemplar results are shown in Figure 1. During isometric dorsiflexion MVC participants displayed a voluntary activation of $97 \pm 2 \%$. No differences in mean torque output or total contraction area were detected between concentric contractions at any of the three contraction speeds and their respective isometric matched contractions $(10 \mathrm{~m}, 20 \mathrm{~m}, 50 \mathrm{~m})(\mathrm{p}>0.05)$. All isometric contractions of $10 \mathrm{~m}, 20 \mathrm{~m}, 50 \mathrm{~m}$ were significantly lower than isometric MVC for both mean torque output $(\mathrm{p}<0.01)$ and total contraction area $(\mathrm{p}<0.05$ to $\mathrm{p}<0.01)$. Similarly, concentric contractions of 10,20 , and $50 \%$ s were significantly lower than isometric MVC for mean torque output $(p<0.05$ to $p<0.01)$ and total contraction area $(\mathrm{p}<0.05$ to $\mathrm{p}<0.01)$. No significant differences were detected between concentric contractions of $10 \% \mathrm{~s}, 20 \%$ and $50 \%$ s for mean torque output ( $\mathrm{p}>0.05)$ and total contraction area $(p>0.05)$. No significant differences were found in peak twitch torque following passive joint movement at $10 \% / \mathrm{s}(4.7 \mathrm{Nm}, \mathrm{p}>0.05), 20 \% \mathrm{~s}(4.4 \mathrm{Nm}, \mathrm{p}>0.05)$ and $50 \% \mathrm{~s}(4.5 \mathrm{Nm}, \mathrm{p}>0.05)$ for the associated repetitions and baseline peak twitch torque values $(4.5 \mathrm{Nm})$.

\section{Surface electromyography (sEMG)}

There was a significantly larger normalized sEMG RMS in the tibialis anterior (TA) between concentric contractions at $10 \%, 20 \%$ and $50 \%$ and the respective isometric matched contractions $(10 \mathrm{~m}, 20 \mathrm{~m}, 50 \mathrm{~m})($ all $\mathrm{p}<0.01)$ (Table 1, Figure 1). However, no significant differences in soleus (antagonist) normalized sEMG were detected between concentric contractions at $10 \% \mathrm{~s}(\mathrm{p}>0.05)$, and $20 \% \mathrm{~s}(\mathrm{p}>0.05)$ and their respective isometric matched contractions $(10 \mathrm{~m}, 20 \mathrm{~m})$, but $50 \%$ s was significantly larger than $50 \mathrm{~m}(\mathrm{p}<0.05)$. Isometric MVC normalized TA sEMG amplitude was significantly larger than $10 \mathrm{~m}, 20 \mathrm{~m}$, and $50 \mathrm{~m}$ (all p<0.01). For coactivation, no significant differences in soleus normalized sEMG were found between $10 \mathrm{~m}, 20 \mathrm{~m}, 50 \mathrm{~m}$ and isometric MVC. Isometric MVC had a significantly lower TA normalized sEMG RMS compared with concentric contractions at all 3 speeds $(\mathrm{p}<0.01)$. However, no differences were detected between concentric contractions of $10 \% \mathrm{~s}, 20 \% \mathrm{~s}, 50 \% \mathrm{~s}$ and isometric 
MVC for soleus normalized sEMG (all $\mathrm{p}>0.05$ ). No significant differences were detected between all concentric contraction speeds for normalized TA or soleus sEMG amplitudes, (all $\mathrm{p}>0.05)$

Muscle twitch properties immediately following CCs

Mean twitch characteristics are presented in Table 1 and exemplar twitch responses are shown in Figure 2. No differences were found in peak twitch torque or maximal RTD between 10m, 20m, $50 \mathrm{~m}$ and baseline peak twitch values (all p>0.05). However, $10 \%$ s, 20\%, $50 \%$ s and isometric MVC were significantly larger than baseline peak twitch torque (all $\mathrm{p}<0.05)$ and faster for maximal RTD (all p<0.05). Additionally, concentric contractions at $10^{\circ} / \mathrm{s}, 20 /{ }^{\circ} \mathrm{s}, 50 \% \mathrm{~s}$ were significantly larger than their respective isometric matched contractions $(10 \mathrm{~m}, 20 \mathrm{~m}, 50 \mathrm{~m})$ for peak twitch torque $(\mathrm{p}<0.01)$ and faster for maximal RTD values $(\mathrm{p}<0.01)$. No differences were found for peak twitch torque or maximal RTD values between concentric contractions at all speeds $10 \%$, $20 \% \mathrm{~s}$ and $50 \%$ s and isometric MVC (all p>0.05). Isometric matched contractions (10m, 20m and 50m) were significantly lower than isometric MVC for peak twitch torque $(\mathrm{p}<0.05$ to $\mathrm{p}<0.01)$ and had a slower maximal RTD $(\mathrm{p}<0.05)$.

\section{Twitch PAP decay}

After the conditioning contraction, peak twitch torque was significantly larger in concentric contractions of $10 \% \mathrm{~s}$ and $50 \% \mathrm{~s}$ than their isometric matches $(10 \mathrm{~m}$ and $50 \mathrm{~m})$ for time points from $1 \mathrm{~s}$ to $45 \mathrm{~s}(\mathrm{p}<0.05$ to $\mathrm{p}<0.01)$, but there was no significant difference at 60 s to $120 \mathrm{~s}(\mathrm{p}>0.05)$. Peak twitch torque was significantly larger in the concentric contraction at $20 \% \mathrm{~s}$ than $20 \mathrm{~m}$ at $1 \mathrm{~s}$ to $60 \mathrm{~s}(\mathrm{p}<0.01)$ after the conditioning contractions, but there was no difference at $90 \mathrm{~s}(\mathrm{p}>0.05)$ or $120 \mathrm{~s}(\mathrm{p}>0.05)$. No significant differences in peak twitch torque were detected between concentric contractions of $10 \% \mathrm{~s}(\mathrm{p}>0.05), 20^{\circ} / \mathrm{s}(\mathrm{p}>0.05)$ and $50^{\circ} / \mathrm{s}(\mathrm{p}>0.05)$ and isometric MVC at any time intervals. These data are not graphically displayed. 


\begin{tabular}{|c|c|c|c|c|c|c|c|c|}
\hline $\begin{array}{l}\text { Voluntary } \\
\text { measures }\end{array}$ & Baseline & $10_{\mathrm{m}}$ & $20_{\mathrm{m}}$ & $50_{\mathrm{m}}$ & $10^{\circ} / \mathrm{s}$ & $20^{\circ} / \mathrm{s}$ & $50^{\circ} / \mathrm{s}$ & MVC \\
\hline $\begin{array}{l}\text { Mean torque } \\
(\mathrm{Nm})\end{array}$ & NA & $\begin{array}{l}17.5 \pm \\
6.2 \dagger \\
(65 \%)\end{array}$ & $\begin{array}{l}16.6 \pm \\
4.7^{\dagger} \\
(61 \%)\end{array}$ & $\begin{array}{l}13.1 \pm \\
4.7 \dagger \\
(49 \%)\end{array}$ & $\begin{array}{l}19.0 \pm \\
5.7 \dagger \\
(70 \%)\end{array}$ & $\begin{array}{l}17.3 \pm \\
5.4 \dagger \\
(64 \%)\end{array}$ & $\begin{array}{l}13.1 \pm \\
5.0^{\dagger} \\
(49 \%)\end{array}$ & $\begin{array}{l}27.0 \pm \\
17.7\end{array}$ \\
\hline $\begin{array}{l}\text { Total } \\
\text { contraction } \\
\text { area (Nm.s) }\end{array}$ & NA & $\begin{array}{l}96 \pm \\
32.2 \dagger \\
(68 \%)\end{array}$ & $\begin{array}{l}93.5 \pm \\
33.2 \dagger \\
(66 \%)\end{array}$ & $\begin{array}{l}76.1 \pm \\
24.3 \dagger \\
(54 \%)\end{array}$ & $\begin{array}{l}95.2 \pm \\
30.5 \dagger \\
(68 \%)\end{array}$ & $\begin{array}{l}92.2 \pm \\
30.1 \dagger \\
(65 \%)\end{array}$ & $\begin{array}{l}70.3 \pm \\
20.1 \dagger \\
(50 \%)\end{array}$ & $\begin{array}{l}141.0 \pm \\
38.1\end{array}$ \\
\hline \multicolumn{9}{|l|}{$\begin{array}{l}\text { sEMG } \\
\text { (RMS) }\end{array}$} \\
\hline TA & NA & $\begin{array}{l}53.7 \pm \\
11.2 \% \dagger\end{array}$ & $\begin{array}{l}47.3 \pm \\
8.0 \% \dagger\end{array}$ & $\begin{array}{l}38.1 \pm \\
7.9 \% \dagger\end{array}$ & $\begin{array}{l}128.9 \pm \\
21 \% * \dagger\end{array}$ & $\begin{array}{l}124.7 \pm \\
27.6 \% * \dagger\end{array}$ & $\begin{array}{l}127.7 \pm \\
26.1 \% * \dagger\end{array}$ & $100.0 \%$ \\
\hline SOL & NA & $\begin{array}{l}23.6 \pm \\
13.3 \%\end{array}$ & $\begin{array}{l}27.2 \pm \\
12.7 \%\end{array}$ & $\begin{array}{l}23.9 \pm \\
13.3 \%\end{array}$ & $\begin{array}{l}47.5 \pm \\
12.3 \%\end{array}$ & $\begin{array}{l}45.0 \pm \\
11.7 \%\end{array}$ & $\begin{array}{l}43.6 \pm \\
11.3 \% *\end{array}$ & $\begin{array}{l}41.0 \pm \\
10.8 \%\end{array}$ \\
\hline \multicolumn{9}{|l|}{$\begin{array}{l}\text { Twitch } \\
\text { properties }\end{array}$} \\
\hline $\mathrm{Pt}(\mathrm{Nm})$ & $4.5 \pm 1.9$ & $\begin{array}{l}5.4 \pm \\
2.4 \dagger \\
(120 \%)\end{array}$ & $\begin{array}{l}5.1 \pm \\
2.2 \dagger \\
(113 \%)\end{array}$ & $\begin{array}{l}4.9 \pm \\
1.0 \dagger \\
(109 \%)\end{array}$ & $\begin{array}{l}7.9 \pm \\
2.8^{* \dagger} \\
(175 \%)\end{array}$ & $\begin{array}{l}7.7 \pm \\
3.0^{* \dagger} \\
(171 \%)\end{array}$ & $\begin{array}{l}7.1 \pm \\
1.9^{* \dagger} \\
(158 \%)\end{array}$ & $\begin{array}{l}7.1 \pm 2.8 \\
(158 \%)\end{array}$ \\
\hline $\begin{array}{l}\text { RTD } \\
(\mathrm{Nm} / \mathrm{ms})\end{array}$ & $\begin{array}{l}0.13 \\
\pm 0.06\end{array}$ & $\begin{array}{l}0.16 \pm \\
0.07 \\
(123 \%)\end{array}$ & $\begin{array}{l}0.15 \pm \\
0.06 \\
(115 \%)\end{array}$ & $\begin{array}{l}0.15 \pm \\
0.07 \\
(115 \%)\end{array}$ & $\begin{array}{l}0.24 \pm \\
0.08 \\
(185 \%)\end{array}$ & $\begin{array}{l}0.25 \pm \\
0.09 \\
(192 \%)\end{array}$ & $\begin{array}{l}0.25 \pm \\
0.09 \\
(192 \%)\end{array}$ & $\begin{array}{l}0.23 \pm \\
0.06 \\
(177 \%)\end{array}$ \\
\hline
\end{tabular}

Table 1. Voluntary and stimulated contractile measurements and surface electromyography. Baseline refers to values before any conditioning contractions. $10 \mathrm{~m}, 20 \mathrm{~m}$ and $50 \mathrm{~m}$ refer to isometric matched contractions to each dorsiflexion isokinetic speed (10, 20 and $50 \%$ s). MVC refers to a $5 \mathrm{~s}$ maximal voluntary isometric dorsiflexion contraction. Mean torque is the average torque value over the $5 \mathrm{~s}$ contraction, total contraction area refers to the area under the torque line. Percentage values (\%) for torque and area relative to the MVC. TA is tibialis anterior and SOL is the soleus muscle. RMS is the root-mean-squared surface electromyography (sEMG) amplitude. Percentage values (\%) for the TA are presented relative to the dorsiflexion MVC. SOL percentage values are relative to the RMS during a maximal plantar flexion isometric MVC. Pt is the peak twitch torque and RTD $(\mathrm{Nm} / \mathrm{ms})$ is the maximal rate of torque development. Percentage values (\%) refers to the relative increase from baseline twitch properties. *denotes significant difference to isometric match; $\uparrow$ denotes significant difference to MVC. All data are expressed as mean \pm standard deviation. 
A

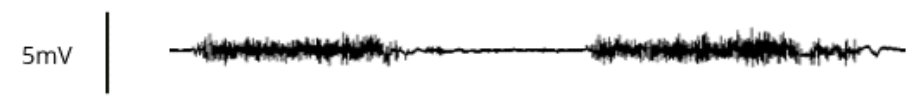

B

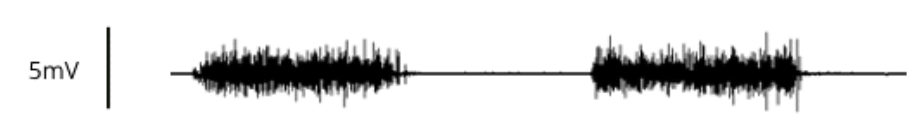

C
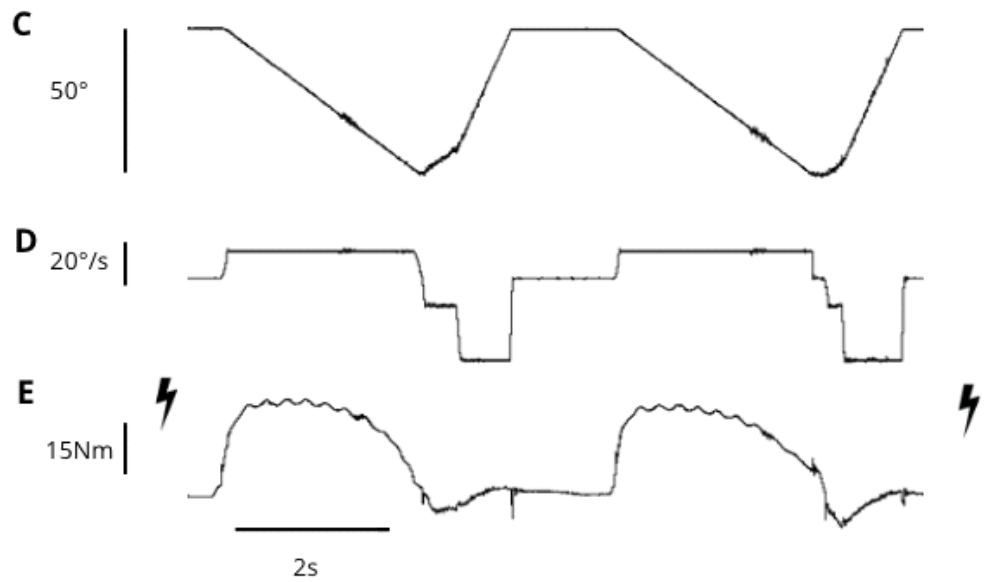

Figure 5. Example surface electromyography and kinematic data of two maximal dorsiflexion isokinetic concentric contractions at $20 \%$ s. A: Unprocessed bipolar surface electromyography recorded from the soleus (antagonist). B: Unprocessed bipolar surface electromyography recorded from the tibialis anterior (agonist). C: Joint position in degrees $\left({ }^{\circ}\right)$. D: Velocity in $\%$ s. E: Voluntary concentric torque output in Nm. Peripheral nerve stimulation (jagged arrows) was done before and after the contractions to produce a baseline and potentiated twitch responses, (see twitch responses in figure 6).
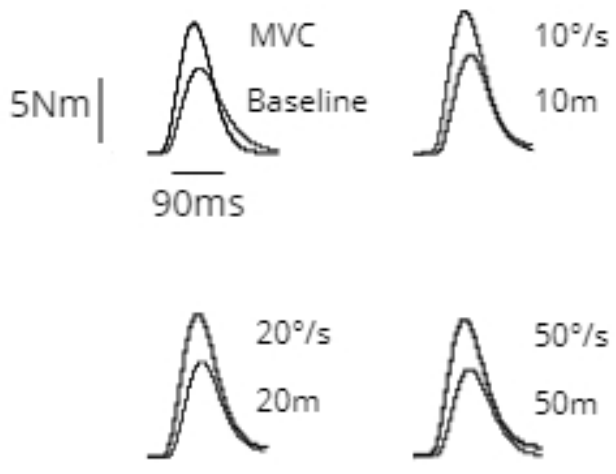

Figure 6. Example of muscle twitch responses after conditioning contractions (CC). Twitch following an isometric maximal voluntary contraction (MVC) compared with a baseline twitch. Twitches following a $10 \%$, $20 \% \mathrm{~s}$ and $50 \%$ s concentric CCs compared respectively with isometric twitch matches at $10 \mathrm{~m}, 20 \mathrm{~m}$, and $50 \mathrm{~m} \mathrm{CC}$. 


\section{Chapter 3}

\section{Discussion and summary}

\subsection{Discussion}

The purpose of this study was to characterize the effect of maximal concentric CCs at three speeds $(10,20$ and $50 \%$ s) on the PAP response measured by twitch potentiation. In addition, the PAP response induced through concentric contractions was compared with the PAP response of isometric MVCs matched for contraction time. The amount of PAP induced from the concentric contractions was not affected by speed and was not significantly different than an isometric MVC sustained for the same duration. When concentric CCs were matched with isometric CCs for torque, contraction times and areas, concentric contractions at all speeds produced significantly larger potentiated peak twitch torques (49 to 58\%) and faster maximal RTD (55 to $77 \%$ ) than their respective isometric contractions.

Each maximal effort concentric contraction set had a significantly lower mean torque output $(\sim 30-50 \%)$ and total contraction area $(\sim 30-45 \%)$ than the isometric MVC despite the contractions being matched for contraction time $(5 \mathrm{~s})$. Because contractile force production is dependent on the number of formed cross-bridges, as muscle length changes (concentric) the number of active cross-bridges (Piazzesi et al. 2007) are fewer with concurrent changes in actinmyosin overlap (Huxley 1957). Throughout the active ROM of a concentric contraction the shortening muscle lengths lead to sub-optimal actin-myosin overlap reducing active torque production. This difference in cross-bridge interactions explains why torque output in maximal effort concentric contractions is lower when compared with isometric MVC contractions (Blix 1894; Edman 1966; Gordon et al., 1966). Despite differences in torque production there was no difference in the PAP response across all concentric speeds and concentric CCs were not different from the isometric MVC condition (Table 1). One study in human dorsiflexors showed that a slow $(5 \%)$ maximal effort concentric contraction produced a similar PAP response as an isometric MVC when matched for contraction time (6 seconds), over a $30^{\circ}$ ROM (Baudry \& Duchateau 2004). Contrary to our hypothesis and despite speculation by Baudry \& Duchateau (2004), we found that the amount of PAP (twitch peak torque and RTD) following concentric 
contractions was unaffected by varying velocity (Table 1). Although concentric contractions have greater amounts of $\mathrm{Ca}^{2+}$ within the myoplasm (Allen \& Kurihara 1982; Ashley \& Moisecu 1975; Housmans et al. 1983; Lab et al. 1984; Stephenson \& Wendt 1984) the $\mathrm{Ca}^{2+}$ dependent process of PAP may already be saturated during an isometric $\mathrm{MVC}$, thus $\mathrm{Ca}^{2+}$ increases above that threshold do not equate to a larger PAP response. During all contraction types $\mathrm{Ca}^{2+}$ is released from the SR and binds with calmodulin activating skeletal myosin light chain kinase which phosphorylates the myosin regulatory light chains (Blumenthal \& Stull 1980; Levine et al., 1991) producing a potentiated response. Although there may be more free $\mathrm{Ca}^{2+}$ during concentric contraction (Allen \& Kurihara 1982; Ashley \& Moisecu 1975; Housmans et al. 1983; Lab et al. 1984; Stephenson \& Wendt 1984) the threshold to reach a maximal PAP response is likely achieved during a maximal isometric MVC thus displaying no differences between concentric CCs at all velocities. We showed no differences in potentiated peak torque and RTD among the three concentric contraction speeds (Table 1). This lack of difference among velocities in vivo may be due a limited assessment of the velocity range available. Maximal rates of dorsiflexion concentric ankle joint velocity with a moderate resistance (20\% MVC) can achieve speeds of $\sim 175 \%$ s (McNeil \& Rice 2007). The challenge for testing faster speeds in this model is the decrease in active contraction time before the joint reaches the end of the ROM, thus high repetition counts are needed to match the torque time integral and therefore potentially inducing fatiguing factors which may confound the PAP response.

Maximal concentric CCs also were compared to isometric CCs matched for mean torque, contraction times and areas. When matched for these torque related parameters, concentric CCs at all speeds had a significantly greater PAP response demonstrated through a larger potentiated peak twitch torque $(55 \%, 58 \%$, and $49 \%$, respectively) and also faster maximal RTD (62\%, 77\% and $77 \%$, respectively) than their isometric match (Table 1, Figure 2). Although torque related parameters were matched, muscle activation was not. Due to the mechanical disadvantage of a concentric movement (Piazzesi et al., 2007) isometric matched contractions require less activation to reach similar torque levels, which is indicated by a significantly lower sEMG signal (Table 1). Therefore, the larger PAP response following concentric CCs compared to isometric matched contractions is likely related to differences in activation rather than the contraction modality. As outlined, the $\mathrm{Ca}^{2+}$ dependent process of PAP is likely saturated under maximal 
activation regardless of contraction type. However, the $\mathrm{Ca}^{2+}$ (Allen \& Kurihara 1982; Ashley \& Moisecu 1975; Housmans et al. 1983; Lab et al. 1984; Stephenson \& Wendt 1984) and crossbridge differences (Piazzesi et al. 2007) between contraction types may be more apparent under submaximal activation at pre- saturated $\mathrm{Ca}^{2+}$ levels. The effect of submaximal isometric CCs is well understood (Vandervoort et al. 1983), conversely, it is unknown whether concentric CCs follow a similar intensity threshold $(\sim 75 \% \mathrm{MVC})$ to produce a substantial or maximal PAP response (Vandervoort et al. 1983).

There are several history-dependent torque altering mechanisms following voluntary related to movement and muscle length changes (Abbot \& Aubert 1952). We found that following passive movement through the range of motion at each speed $(10,20$ and $50 \%$ s) for the given repetition count there was no statistical difference in peak twitch torque compared to baseline values. Additionally non-passive history-dependent actions such as residual torque enhancement (rTE) or depression (rTD) (Abbot \& Aubert 1952) likely had no effect on our concentric twitch responses because rTE is present after active muscle lengthening and participants were instructed to relax after active shortening to allow the joint angle to return passively to the start. Furthermore, twitch characteristics were measured at the starting joint angle and not at the end of active shortening ROM thus rTD is also unlikely to affect the twitch response in the present study. Thus, increase in twitch torque and RTD following voluntary concentric contractions were related to PAP and likely not effected by other history-dependent mechanisms.

The coexistence of potentiation and fatigue illustrates (Rassier \& MacIntosh 2000) the importance of the interplay between contraction intensity and duration in producing a large amount of PAP and has been well described in isometric models (Fukutani et al. 2012; Fukutani et al. 2014; Vandervoort et al. 1983). However, this relationship is confounded in dynamic contractions as additional variables become relevant such as contraction speed, repetition count and ROM. Thus, equivalent comparisons are further challenged with these additional factors. In relation to this, concentric contractions induce greater peripheral muscle fatigue than isometric contractions (Babult et al. 2006); likely due to the decreased metabolic efficiency in concentric contractions when matched with similar isometric contraction intensities (Ryschon et al. 1997). 
In the current study the $5 \mathrm{~s}$ CC time was chosen to minimize effects of repetition number and fatigue on the PAP response (Babault et al. 2006). Furthermore, concentric contractions often display higher sEMG activity than isometric contractions when matched for torque output (Madeleine et al. 2001), and indeed we found higher agonist (tibialis anterior) sEMG during concentric compared to isometric contractions in all conditions $(10 \mathrm{~m}, 20 \mathrm{~m}, 50 \mathrm{~m}$ and MVC). Although there was a trend for antagonist (soleus) sEMG to be greater during concentric compared to isometric matched contractions (10m, $20 \mathrm{~m}$ and $50 \mathrm{~m})$, it was only significant between $50 \% \mathrm{~s}$ and $50 \mathrm{~m}$. This indicates that there is a greater neural drive to agonist muscles during concentric compared to isometric contractions and that higher antagonist activity during concentric contractions may be a compensatory response to stabilize the joint during dynamic movement. Contrary to our findings, however, higher sEMG in concentric contractions compared to isometric is not always present (Babault et al. 2001). The differing sEMG results between studies is unclear but may be a limitation of sEMG during dynamic movements, such as electrode shift (Farina 2006). Additionally, motor unit firing rates are higher during high velocity concentric contractions compared to maximal isometric contractions (Cowling et al. 2016; Harwood et al. 2011), and likely contribute to the higher sEMG response found in the present study.

Following CCs the PAP response will immediately be maximal and subsequently begin to dissipate and this process is observed by intermittent twitch measurements. Peak twitch torque following concentric CCs at each speed (10,20 and 50\%) trended larger than their respective isometric match contraction throughout the entire 120s of twitch decay. However, concentric CCs of 10 and $50 \%$ s were only significantly larger than their isometric match for the initial $45 \mathrm{~s}$ after the CC, and at $60 \mathrm{~s}$ for $20 \%$, and concentric CCs were not significantly different than an isometric MVC at any time point. The dissipation of PAP is by the dephosphorylation of MRLCs and is governed by a phosphatase (Sweeney et al. 1993). This phosphatase removes the phosphate from the MRLCs returning the myosin orientation to its resting state (Sweeney et al. 1993). Thus, despite PAP being greater following concentric contractions and for the initial 45 60 s afterwards, the relative decline or decay of the enhancement was similar to matched isometric contractions and after 60s there were no statistical differences. Because the initial PAP 
response is similar between all concentric contractions and an isometric MVC it is reasonable to observe a similar dissipation rate of the PAP response between these contractions.

\subsection{Conclusion}

This study characterized the effect of concentric CCs at three speeds (10,20 and 50\% $)$ on the PAP response measured by twitch potentiation. The principal finding was that the PAP response following maximal concentric CCs was independent of contractile speed. Secondarily, concentric CCs at all speeds were not significantly different than an isometric MVC matched for time. Although concentric CCs at varying speeds and an isometric MVC have differing $\mathrm{Ca}^{2+}$ and cross-bridge kinetics, the $\mathrm{Ca}^{2+}$ dependent mechanism of PAP is likely saturated at all maximal contractions regardless of modality (isometric or concentric). Concentric CCs at all speeds produced a significantly larger PAP response than their isometric $\mathrm{CC}$ when matched for mean torque, contraction time and area. However, this difference is likely related to muscle activation rather than the contraction modality. Further investigation into submaximal concentric CCs is warranted as differences within the PAP response may be only at submaximal contraction intensities, under submaximal $\mathrm{Ca}^{2+}$ levels. During dynamic contractions other factors and variables are important to understand in relation to PAP and the optimal relationship between torque output and contraction time in this task requires further study, and to fully determine the effect of contractile shortening speed. Indeed, the potential effect of other history-dependent competing factors such as fatiguing processes may have a different role in dynamic tasks compared with isometric actions in relation to PAP.

\subsection{Limitations}

Understanding concentric contractions has direct implications in daily human movements, however, studying neuromuscular aspects of concentric contractions has several technical limitations related to mechanical changes in the system and the influence of additional kinematic parameters such as velocity and ROM. Surface EMG was used to record global myoelectrical activity of tibialis anterior and soleus muscle groups. Under isometric conditions the actively contracting muscle fibres remain relatively constant in relation to the overlying skin. However, 
during concentric movement the fixed electrodes do not move in relation to the underlying shortening contractions and thus different regions of the muscle are contributing to the surface signal throughout the range of movement. Using an indwelling wire electrode would overcome this limitation as it is inserted directly into the muscle and follows the fibres as they shorten. However, indwelling wire electrodes also have limitations. Most notably, the electrode records from a small area relative to the whole muscle (Basmajian \& Stecko 1962) and thus data through indwelling electrodes may be less representative of the whole contracting muscle.

Voluntary activation (VA) was assessed during a maximal isometric contraction which is commonly done. However, it is challenging to assess VA during concentric movement and this was not done in the present study due to mechanical limitations of the dynamometer and joint angle ROM chosen. Specifically, it is necessary for the resting (control) and interpolated twitch to be delivered at a fixed horizontal plane $\left(90^{\circ}\right)$ during passive (control) or active (interpolated) dynamometer movement (Gandevia et al. 2004). However, during active shortening there is minimal time for a participant to achieve maximal activation when starting at $115^{\circ}$ plantar flexion. Additionally, during resting twitches with passive dynamometer movement not all participants produced a large enough twitch response for a reliable assessment of VA. Therefore, it is unknown whether participants could fully activate during concentric contractions at all three speeds. To address this potential concern indirectly, on a separate testing day before the main measures, participants were practiced in making strong and consistent concentric contractions throughout the entire ROM. As isometric VA was maximal ( 97\%) and participants were familiarized with the contractions, it is likely participants could achieve maximal activation during concentric contractions.

The present study induced PAP through slow and moderate velocity concentric CCs. Although the velocities used were substantially faster than in the few past reports at up to $50 \%$, the dorsiflexors have a potential joint rotation of $\sim 175 \%$ s (loaded at 20\%MVC) (McNeil \& Rice 2007) and thus the PAP response after higher maximal velocity conditioning contractions is unknown. The limitation with near maximal velocities is the decrease in time of active contraction throughout the ROM. As a result, increased repetitions would be required to match 
contraction times between conditions potentially causing muscle fatigue. As described, isometric and concentric contractions have differing fatiguing mechanisms.

Both males and females were tested in the present study. However, due to the limited number of female participants differences in the PAP response could not be statistically compared between sexes. Females can display a lower PAP response than males (Paasuke et al. 2002) but this is not always found (Simpson et al. 2018). Differences in fibre type (Miller et al. 1993), tendon compliance (Onambélé et al. 2007) and neuromuscular control (Inglis \& Gabriel 2021) may cause differing PAP responses following concentric contractions between sexes. Thus, systematically exploring sex differences in the PAP response following dynamic CCs is warranted.

\subsection{Future directions}

The current investigation advanced the understanding of PAP following concentric CCs. Conversely, investigation into the PAP response following eccentric (lengthening) contractions at moderate and high velocities would be especially interesting to explore. Eccentric contractions occur in daily movement and little is known about the PAP response following these movements as only one previous study has explored this concept (Baudry \& Duchateau 2004) which was done at very slow speeds $5 \%$ s. Eccentric contractions have differing cross-bridge kinetics (Flitney \& Hirst 1978) and activation patterns (Enoka 1996) than concentric and isometric contractions.

The effect of submaximal isometric CCs on the PAP response is well known, but the effect of submaximal concentric contractions has not been investigated. Therefore, it is unknown whether concentric CCs follow a similar intensity threshold ( $>75 \% \mathrm{MVC})$ (Vandervoort et al. 1983) to produce a significant PAP response. Isometric CCs to induce PAP have been well studied as the optimal relationship between PAP and fatigue can be assessed by manipulating contraction intensity or duration. However, during dynamic movement other variables may impact the PAP response such as repetitions, ROM and velocity. Understanding the relationship between these variables with PAP and fatigue will provide additional insight into concentric conditioning 
contractions and the importance of the interplay between fatigue-inducing actions compared with acute force enhancements (PAP).

The present study used dorsiflexion as the contraction modality. The TA is the primary contributor to dorsiflexion torque ( $40-60 \%)$ and is mainly composed of Type I fibres ( $75 \%)$ (Fukunaga et al. 1996; Johnson et al. 1973; Marsh et al. 1981). It is well established that muscles composed of a greater percent of Type II fibres have a greater PAP capacity (Houston \& Grange 1991; Moore \& Stull 1984). Thus, it is unknown if muscles composed predominantly of Type II fibres would have a similar response to slow and moderate velocity concentric CCs. The triceps brachii is predominantly composed of Type II fibres ( 65\%) (Johnson et al. 1973) and is the primary elbow extensor. Therefore, a future study using concentric elbow extension to induce PAP would provide insight into the influence of fibre type composition and PAP following concentric CCs.

The decrease in PAP capability with age is well documented (Petrella et al. 1989). However, it is unknown how a dynamic (concentric or eccentric) CC would influence the PAP response in aged individuals. Due to aged-related changes in contractile properties (Vandervoort \& McComas 1986), kinetics (Höök et al. 1999) and with motor unit remodelling (McNeil et al. 2005) relationships between PAP, fatigue and velocity may be modified when tested in different adapted states such as aging. 


\section{References}

Abbott, B.C., Aubert, X.M. The force exerted by active striated muscle during and after change of length. J Physiol 117(1):77-86, 1952.

Ashley, CC. \& Moisescu D.G. The part played by $\mathrm{Ca}^{2+}$ in the contraction of isolated bundles of myofibrils. Calcium Transport in Contraction and Secretion, 517-525, 1975.

Allen, D.G. \& Kurihara, S. The effects of muscle length on intracellular calcium transients in mammalian cardiac muscle. J Physiol Lond 327: 79-94, 1982.

Azam, M., Wehrle, C.J, Shaw, P.M. Anatomy, bony pelvis and lower limb, tibial nerve. Stats pearl publishing, treasure island (FL), 2020.

Balnave C.D. \& Allen DG. The effect of muscle length on intracellular calcium and force in single fibres from mouse skeletal muscle. J Physiol 415:433-458, 1996.

Babault, N., Pousson, M., Ballay, Y., Van Hoecke, J. Activation of human quadriceps femoris during isometric, concentric, and eccentric contractions. J Appl Physiol 91(6):2628-2634, 2001.

Babault, N., Desbrosses, K., Fabre, M.S., Pousson, M. Neuromuscular fatigue development during concentric and isometric knee extensions. J Appl Physiol 100(3):780-785, 2006.

Barany, M. ATPase activity of myosin correlated with speed of muscle shortening. J Gen Physiol 50:197-218, 1967.

Basmajian, J.V. \& Stecko, G. A new bipolar electrode for electromyography. J Appl Physiol 17:849, 1962.

Baudry, S., Duchateau, J. Postactivation potentiation in human muscle is not related to the type of maximal conditioning contraction. Muscle Nerve 30 (3):328-336, 2004.

Bers, D.M. Ca transport during contraction and relaxation in mammalian ventricular muscle. Basic Res Cardiol 92(1):1-10, 1997.

Bers, D.M. Cardiac excitation-contraction coupling. Nature 415 (6868): 198-205, 2002.

Blazevich, A.J. \& Babault, N. Post-activation potentiation versus post activation performance enhancement in humans: historical perspective, underlying mechanisms and current issues, Front Physiol. 10: 1359, 2019.

Blix, M. Die Lange und die Spannung des Muskels. Skand Arch Physiol, 5:173-206, 1894.

Blumenthal, D.K. \& Stull, J.T. Activation of skeletal muscle myosin light chain kinase by $\mathrm{Ca}^{2+}$ and calmodulin. Biochemistry 19: 5608-5614,1980. 
Bottinelli, R., Canepari, M., Reggiani, C., Stienen, G.J.M. Myofibrilar ATPase activity during isometric contraction and isomyosin composition in rat single skinned muscle fibres. $J$ Physiol (Lond) 481:663-675, 1994b.

Boullosa, D., Beato, M., Dello Iacono, A., Cuenca-Fernandez, F., Doma, K., Schumann, M., Moura Zagatto A.M., Loturco, I., Behm, BG. A new taxonomy for post-activation potentiation in sport. Int J Sports Physiol Perform 15:8 1197-1200, 2020.

Brand P.W., Beach D.E., Thompson D.E. Relative tension and potential excursion of muscles in the forearm and hand, $J$ Hand surgery, 3: 209-219, (1981)

Brown, G. \& Von Euler, U. The after effect of a tetanus on mammalian muscle. J Physiol 93, 39-60, 1938.

Bruton, J.D., Place, N., Yamada, T., Silva, J.P., Andrade, F.H., Dahlstedt, A.J., Zhang, S.J., Katz, A., Larsson, N.G., Westerblad, H. Reactive oxygen species and fatigue-induced prolonged low-frequency force depression in skeletal muscle fibres in rats, mice and SOD2 overexpressing mice, J Physiol 586: 175-184, 2008.

Burke, R., Rudomin, P., Zajac, F. The effect of activation history on tension production in individual muscle units, Brain Res 109: 515-529 , 1976.

Cheng, A.J., Bruton, J.D., Lanner, J.T., Westerblad, H. (2015) Antioxidant treatments do not improve force recovery after fatiguing stimulation of mouse skeletal muscle fibres. $J$ Physiol 593: 457-475, 2015.

Close, R. Properties of motor unit in fast and slow skeletal muscle of the rat. $J$ Physiol (Lond) 193:45-55, 1967.

Cowling, B.L., Harwood, B., Copthorne, D.B., Rice, C. L. Rate modulation of human anconeus motor units during high-intensity dynamic elbow extensions. J Appl Physiol 121:475$482,2016$.

Cuenca-Fernandez, F., Smith, I.C., Jordan, M.J., MacIntosh, B.R., Lopez-Contreras, G., Arellano, R., Herzog, W. (2017) Nonlocalized postactivation performance enhancement (PAPE) effects in trained athletes: a pilot study. Appl Physiol. Nutr. Metab 42,1122-1125, 2017.

De Luca, C.J. The use of surface electromyography in biomechanics. J Appl Biomechan 13: 135-163, 1997.

Edman, K.A.P. The relation between sarcomere length and active tension in isolated semitendinosus fibres of the frog. J Physiol 183(2):407-417, 1966.

Edwards, R.H.T, Hill, D.K., Jones, D.A., Merton, P.A. Fatigue of long duration in human skeletal muscle after exercise. J Physiol 272: 769-778, 1977. 
Enoka, R.M. Eccentric contractions require unique activation strategies by the nervous system. $J$ Appl Physiol 81(6): 2339-2346.

Fabiato, A., \& Fabiato, F. Dependence of the contractile activation of skinned cardiac cells on the sarcomere length. Nature Lond, 256, 54-56, 1975 b.

Farina, D. Interpretation of the surface electromyogram in dynamic contractions. Exercise and Sports Science Reviews, 34: 121-127, 2006.

Flitney, F.W. \& Hirst, D.G. Cross-bridge detachment and sarcomere "give" during stretch of active frog's muscle. J Physiol (Lond) 276: 449- 465, 1978.

Fowles, J.R., Green, H.J. Coexistence of potentiation and low-frequency fatigue during voluntary exercise in human skeletal muscle. Can J Physiol Pharmacol 81: 1092-1100, 2003.

Frank, J.S. \& Winegrad, S. Effects of muscle length on Ca efflux in resting and contracting skeletal muscle. Am J Physiol, 231, 555-559, 1976.

Fukunaga, T., Roy, R.R., Shellock, F.G., Hodgson, J.A., \& Edgerton, V.R. Specific tension of human plantar flexors and dorsiflexors. J Appl Physiol 80(1): 158-165, 1996.

Fukutani, A., Hirata, K., Miyamoto, N., Kanehisa, H., Yanai, T., Kawakami, Y. Effect of conditioning contraction intensity on postactivation potentiation is muscle dependent. $J$ Electromyogr Kinesiol 24(2):240-245, 2014.

Fukutani, A., Miyamoto, N., Kanehisa, H., Yanai, T., Kawakami, Y. Influence of the intensity of a conditioning contraction on the subsequent twitch torque and maximal voluntary concentric torque. J Electromyogr Kinesiol 22 (4): 560-565, 2012.

Höök, P., Li, X., Sleep, J., Hughes, S., Larsson, L. In vitro motility speed of slow myosin extracted from soleus fibres of young and old rats. J Physiol 520: 463-471, 1999.

Housmans, P.R., Lee, N.K., \& Blinks, J.R. Active shortening retards the decline of the intracellular calcium transient in mammalian heart muscle. Science 221: 59-161, 1983.

Hui, C.S., \& Gilly, W.F. Mechanical activation and voltage-dependent charge movement in stretched muscle fibres. Nature Lond 281: 223-225, 1979.

Gandevia, S.C. Spinal and supraspinal factors in human muscle fatigue. Physiol Rev 81(4):1725-1789, 2001.

Gandevia, S.C., Herbert, R.D., Leeper, J.B. Voluntary activation of human elbow flexor muscle during maximal concentric contractions, J Physiol 512:2 595-602, 1998. 
Gans, C. \& Bock, W.J. The functional significance of muscle architecture: a theoretical analysis, Ergebisse der Anatomie und Entwicklungsgeschichte 38: 115-142, 1965.

Gans, C. Fiber architecture and muscle function. Exercise and Sports Science Reviews 10: 160207, (1982).

Gittings, W., Huang, J., Smith, I.C., Quadrilatero, J., Vandenboom, R. The effect of skeletal myosin light chain kinase gene ablation on the fatigability of mouse fast muscle, J Muscle Cell Motil 31:337-348, 2011.

Gordon, A.M., Huxley, A.F., Julian, F.J. The variation in isometric tension with sarcomere length in vertebrate muscle fibres. J Physiol 184(1): 170-192, 1966.

Gordon, A.M., Regnier, M., Homsher, E. Skeletal and cardiac muscle contractile activation: tropomyosin 'rocks and roll'. News Physiol Sci 16:49-55, 2001.

Grange, R.W., Vandenboom, R., Houston, M.E. Physiological significance of myosin phosphorylation in skeletal muscle. Can J Appl Physiol 18(3): 229-42, 1993.

Green, H.J., Jones, S.R. Does post-tetanic potentiation compensate for low frequency fatigue? Clin Physiol 9:499-514, 1989.

Guttman, S., Horton, R., Wilber, D. Enhancement of muscle contraction after tetanus. Am J Physiol-Legacy Content 119, 463- 47, 1937.

Hamada, T., Sale, D., MacDougall, J.D., Tarnopolsky, M.A. Interaction of fibre type, potentiation and fatigue in human knee extensor muscles. Acta Physiol Scand 178(2):165-173, 2003.

Hardin, J.M. \& Devendra, S. Anatomy, Bony pelvis and lower limb, calf common peroneal (fibular) nerve. Stats pearl publishing, treasure island (FL), 2020.

Harwood, B., Davidson, A.W., Rice, C.L. Motor unit discharge rates of the anconeus muscle during high-velocity elbow extensions. Exp Brain Res 208(1):103-113, 2011.

Heckman C.J. \& Enoka R.M. Motor Unit, Compr Physiol 2629-2682, 2012.

Henneman, E. \& Mendell, L.M. Functional organization of motoneuron pool and its inputs. In Handbook of physiology section I, the nervous system, V.B. Brooks (ed) Bethesda, MD: Am Physiol Soc, 423-508, 1981.

Hill, A.V. The heat of shortening and the dynamic constants of muscle. Proc R Soc Lon B Biol Sci 126: 136-195, 1938

Housmans, PK., Lee, NK., Blinks, J.R. Active shortening retards the decline of the intracellular calcium transient in mammalian heart muscle, Science 221: 159-161, 1983. 
Houston, M.E. \& Grange, R.W. Torque potentiation and myosin light-chain phosphorylation in human muscle following a fatiguing contraction. Can J Physiol Pharmacol 69:269-273, 1991.

Huxley, A.F. Muscle structure and theories of contraction. Prog Biophys Chem 7: 255-318, 1957.

Hynes, T.R., Block, S.M., White, B.T., Spudich, J.A. Movement of myosin fragments in vitro: domains involved in force production. Cell 48: 953-963, 1987.

Inglis, J.G. \& Gabirel, D.A. Sex differences in the modulation of the motor unit discharge rate leads to reduced force steadiness. Appl Physiol Nutr Met, IN PRESS, 2021.

Jami, L., Murthy, K.S.K., Petit, J., Zytnicki, D. After-effects of repetitive stimulation at low frequency on fast-contracting motor units of cat muscle. J Physiol 340: 129-143, 1983.

Johnson, M.A., Polar, J., Weightman, D., Appleton, D. Data on the distribution of fibre type in thirty-six human muscles an autopsy study, J neurological sciences 18: 111-129, 1973.

Katz, B. The relation between force and speed in muscular contraction. J Physiol 96: 45-64, 1939.

Lab, M.J., Allen, D.G., \& Orchard, C.H. The effects of shortening on myoplasmic calcium concentrations and on the action potential of mammalian ventricular muscle. Circ Res 55, 825$829,1984$.

Larsson, L. \& Moss, R.L. Maximum velocity of shortening in relation to myosin isoform composition in single fibres from human skeletal muscle. J Physiol (Lond) 472:595-614, 1993.

Lehman, W., Craig, R., Viberett, P. $\mathrm{Ca}^{2+}$ induced tropomyosin movement in Limulus thin filaments revealed by three-dimensional reconstruction. Nature 468: 65-67, 1994.

Levine, R.J., Chantler, P.D., Kensler, R.W., Woodhead, K.L. Effects of phosphorylation by myosin light chain kinase on the structure of limulus thick filaments. J Cell Biol 113(3): 563$572,1991$.

Levine, R.J., Kensler, R.W., Yang, Z.H., Stull, J.H., Sweeney, H.L. Myosin light chain phosphorylation affects the structure of rabbit skeletal muscle thick filaments. Biophys $J$ 71(2): 898-907, 1996.

Levine, R.J., Yang, Z., Epstein, N.D., Fananapazir, L., Stull, J.T., Sweeney, H.L. Structural and functional responses of mammalian thick filaments to alterations in myosin regulatory light chains. J Struct Biol 122:149-161, 1998. 
Liddell, E.G.T. \& Sherrington, C.S. Recruitment and some other factors of reflex inhibition. Proc -R Soc Lond B97, 488-518, 1925.

Lorand, L. Adenosine triphosphate-creatine transphosphorylase as relaxing factor of muscle Nature 172: 1181-1183, 1953.

MacIntosh, B.R. \& Gardiner, P.F. Posttetanic potentiation and skeletal muscle fatigue: interactions with caffeine. Can J Physiol Pharmaco 65(2):260-268, 1987.

MacIntosh, B.R. Cellular and Whole Muscle Studies of Activity Dependent Potentiation. Adv Exp Med Biol 682, 315-342, 2010.

Madeleine, P., Bajaj, P., Søgaard, K., Arendt-Nielsen, L. Mechanomyography and electromyography force relationships during concentric, isometric and eccentric contractions. $J$ Electromyogr Kinesiol 11(2):113-121, 2001.

Manning, D.R. \& Stul, J.T. Myosin light chain phosphorylation and phosphorylase a activity in rat extensor digitorum longus muscle. Biochem Biophys Res Commun 90(12):164-170, 1979.

Manning, D.R. \& Stull, J.T. Myosin light chain phosphorylation-dephosphorylation in mammalian skeletal muscle. Am J Physiol 242(3): C234-241, 1982.

McNeil, C.J., Doherty T.J., Stashuk, D.W., Rice, C.L. Motor unit estimated in the tibialis anterior muscle of young, old and very old men. Muscle Nerve 31(4):461-467, 2005.

McNeil, C.J. \& Rice, CL. Fatigability is increased with age during velocity-dependent contractions of the dorsiflexors. J Gerontology 62(6):624-629, 2007.

Miller, A.E.J., MacDougall, J.D., Tarnopolsky, M.A., Sale, D.G. Gender differences in strength and muscle fibre characteristics. Eur J Appl Physiol 66: 254-262, 1993.

Moore, R.L. \& Stull, J.T. Myosin light chain phosphorylation in fast and slow twitch skeletal muscles in situ. Am J Physiol 247(5Pt1): C462-71, 1984.

Muthu, P., Talent, J.M., Gryczynski, I., Borejdo, J. Cross-bridge duty cycle in isometric contraction of skeletal myofibrils, Biochemistry 47: 5657-5667, 2007.

Onambélé, G.N.L., Burgess, K. \& Pearson, S.J. Gender-specific in vivo measurements of the structural and mechanical properties of the human patellar tendon. J Ortho Res 25: 1635-1642, 2007.

Ortenblad, N., SJogaard, G., Madsen, K. Impaired sarcoplasmic reticulum $\mathrm{Ca}^{2+}$ release rate after fatiguing simulation in rat skeletal muscle. J Appl Physiol 89: 210-217, 2000. 
Petrella, R.J., Cunningham, D.A., Vandervoort, A.A., Paterson, D.H. Comparison of twitch potentiation in the gastrocnemius of young and elderly men. Eur J Appl Physiol 58: 395-399, 1989.

Pette D and Staron RS. Myosin isoforms, muscle fiber types, and transitions. Microscopy research and technique 50:500-509, 2000.

Pereschini, A., Stull, J.T., Cooke, R. The effect of myosin phosphorylation on contractile properties of skinned rabbit skeletal muscle fibers. J Biol Chem 260(13): 7951-7954, 1985.

Piazzesi, G., Reconditi, M., Linari, M., Lucci, L., Bianco, P., Brunello, E., Decostre, V., Stewart, A., Gore, D.B., Irving, T.C, Irving, M., Lombard, V. Skeletal muscle performance determined by modulation of number of myosin motors rather than motor force or stroke size. Cell 131(4): 784-795, 2007.

Powell PL, Roy RR, Kanim P, Bello M, Edgerton VR. Predictability of skeletal muscle tension from architectural determinations in guinea pig hindlimbs. Journal of Applied Physiology: Respiratory, Environmental and Exercise Physiology 57: 1715-1721, 1984.

Rankin, L.L., Enoka, R.M., Volz, K.A., Stuart, D.G. Coexistence of twitch potentiation and tetanic force decline in rat hindlimb muscle. J Appl Physiol 65-2687-2695, 1988.

Rassier, D.E.Striated Muscles: From Molecules to Cells. Adv Exp Med Biol 682, 1-7, 2010.

Rassier, D.E., MacIntosh. B.R. Coexistence of potentiation and fatigue in skeletal muscle. Braz J of Med and Biological Res 33:499-508, 2000.

Ryder, J.W., Lau, K.S., Kamm, K.E., Stull, J.T. Enhanced skeletal muscle contraction with myosin light chain phosphorylation by a Calmodulin-sensing kinase. J Biological Chem 282:28, 2007.

Ryschon, T.W., Fowler, M.D., Wysong, R.E., A-R Anthony, Balaban R.S. Efficiency of human skeletal muscle in vivo: comparison of isometric, concentric, and eccentric muscle action. J Appl Physiol 83(3):867-874, 1997.

Sacks R.D. \& Roy R.R. Architecture of hindlimb muscles of cats: functional significance, $J$ morphology 173, 185-195, 1982.

Sale, D.G. Postactivation potentiation: role in human performance. Exerc Sport Sci Rev 30(3):138-143, 2002.

Sandow, A. Excitation-contraction coupling in muscular response. Yale J Biol Med XXV 176201, 1952. 
Seitz, L.B., Mina, M.A., Haff, G.G., Blazevich, A.J. Postactivation potentiation during voluntary contractions after continued knee extensor task-specific practice. Appl Physiol Nutr Metab 40:230-237, 2015.

Smith, C.B., Cheng, A.J., Rice, C.L. Potentiation of the triceps brachii during voluntary submaximal contractions. Muscle Nerve. 43(6):859-911, 2011.

Smith, C.B, Allen, M.D, Rice CL. Coexistence of peripheral potentiation and corticospinal inhibition following a conditioning contraction in human first dorsal interosseous muscle. $J$ Appl Physiol 129-926-931, 2020.

Smith, I.C. \& MacIntosh, B.R. A comment on "A new Taxonomy for post-activation potentiation in sport" International Journal of Sports Physiology and Performance 12(2): 163, 2021.

Spudich, J.A. The myosin swinging cross-bridge model. Nature Reviews Molecular Cell Biology 2: 387-392, 2001.

Stephenson, D.G., \& Wendt, I.R. Length dependence of changes in sarcoplasmic calcium concentration and myofibrillar calcium sensitivity in striated muscle fibres. J Muscle Res Cell Motil 5, 243-272, 1984.

Sweeney, H.L., Stull, J.T. Phosphorylation of myosin in permeabilized mammalian cardiac and skeletal muscle cells. Am J Physiol C657-C660, 1986.

Sweeney, H.L. \& Stull, J.T. Alterations of cross-bridge kinetics by myosin light chain phosphorylation in rabbit skeletal muscle: implications for regulation of actin-myosin interaction. Proc Natl Acad Sci USA 87(1):414-418, 1990.

Sweeney, H.L., Bowman, B.F., Stull, J.T. Myosin light chain phosphorylation in vertebrate striated muscle: regulation and function. Am J Physiol 264(5Pt1), 1993.

Sweeney, H.L., Zang, Z., Zhi, G., Stull, J.T., Trybus, K.M. Charge replacement near the phosphorylatable serine of the myosin regulatory light chain mimics aspects of phosphorylation. Proc Natl Acad Sci USA 91:1490-1494, 1994.

Till, K.A \& Cooke, C. The effects of postactivation potentiation on spring and jump performance of male academy soccer players. J Strength Cond Res 23(7): 1960-1967, 2009.

Todd, G., Gorman, R.B., Gandevia, S.C. Measurement and reproducibility of strength and voluntary activation of lower-limb muscles. Muscle Nerve 29(6):834-842, 2004.

Vandenboom, R., Grange, R.W., Houston, M.E. Threshold for force potentiation associated with skeletal myosin phosphorylation. Am J Physiol 265(6): C1456-C1462, 1993. 
Vandervoort, A.A., Quinlan, J., McComas, A.J. Twitch potentiation after voluntary contraction. Exp Neurol 81:141-152, 1983.

Vandervoort, A.A. \& McComas, A.J. Contractile changes in opposing muscle of human ankle joint with ageing. J Appl Physiol 61: 361-367, 1986.

Weiss A, Schiaffino S, Leinwand LA. Comparative sequence analysis of the complete human sacromeric myosin heavy chain family: implications for functional diversity. J Mol Biol 290: 6175, 1999a.

Westerblad, H., Lee, J.A., Lannergren, J., Allen, D.G. Cellular mechanisms of fatigue in skeletal muscle Am J Physiol C261: C195-C209, 1991.

Wickiewicz T.L, Roy R.R., Powell P.J., Edgerton V.R. Muscle architecture of the human lower limb, Clinical Orthopaedics and Related Research 179: 317-325, 1983.

Xenofondos, A., Patikas, D., Koceja, D.M., Behdad, T., Bassa, E., Eleftherios, K., Kotzamanidis C. Post-activation potentiation: The neural effects of post-activation depression. Muscle Nerve 52: 252-259, 2015.

Yoshioka, T. Width of the junctional gap of the triad at various sarcomere length in frog skeletal muscle. Jap J Physiol 32, 475-479, 1982.

Zimmerman, H.B., MacIntosh, B.R., Dal Pupo, J. Does postactivation potentiation (PAP) increase voluntary performance? Appl Physiol Nutr Metab 45(4):349-356, 2019. 


\section{Appendices}

Appendix A. Ethical Approval

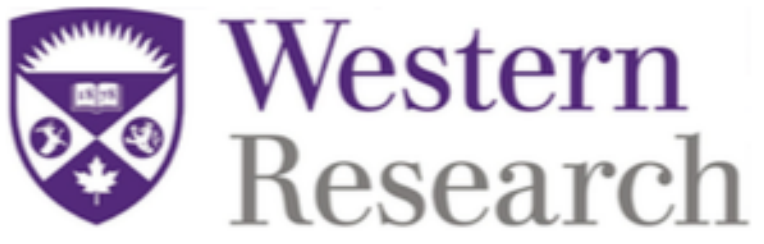

Date: 4 March 2021

To: Charles Rice

Project ID: 107505

Study Title: Motor neuron and muscle fiber resilience in humans

Application Type: Continuing Ethics Review (CER) Form

Review Type: Delegated

REB Meeting Date: 09/March/2021

Date Approval Issued: 04/Mar/2021

REB Approval Expiry Date: 07/Mar/2022

Dear Charles Rice,

The Westem University Research Ethics Board has reviewed the application. This study, including all currently approved documents, has been re-approved until the expiry date noted above.

REB members involved in the research project do not participate in the review, discussion or decision.

Western University REB operates in compliance with, and is constituted in accordance with, the requirements of the Tri-Council Policy Statement: Ethical Conduct for Research Involving Humans (TCPS 2); the International Conference on Harmonisation Good Clinical Practice Consolidated Guideline (ICH GCP); Part C, Division 5 of the Food and Drug Regulations; Part 4 of the Natural Health Products Regulations; Part 3 of the Medical Devices Regulations and the provisions of the Ontario Personal Health Information Protection Act (PHIPA 2004) and its applicable regulations. The REB is registered with the U.S. Department of Health \& Human Services under the IRB registration number IRB 00000940.

Please do not hesitate to contact us if you have any questions.

Sincerely,

The Office of Human Research Ethics

Note: This correspondence includes an electronic signature (validation and approval via an online system that is compliant with all regulations). 
Appendix B. Permissions to reprint previously published manuscript materials.

THE AMERICAN PHYSIOLOGICAL SOCIETY LICENSE

TERMS AND CONDITIONS

Mar 16, 2021

This Agreement between The University of Western Ontario -- Alexander Zero ("You") and The American Physiological Society ("The American Physiological Society") consists of your license details and the terms and conditions provided by The American Physiological Society and Copyright Clearance Center.

License Number $\quad 5026641196291$

License date $\quad$ Mar 12,2021

Licensed Content Publisher The American Physiological Society

Licensed Content

Publication

Am J Physiol-Cell Physiology

Licensed Content Title

Myosin light chain phosphorylation in vertebrate striated muscle: regulation and function

Licensed Content Author

H. L. Sweeney, B. F. Bowman, J. T. Stull

Licensed Content Date May 1, 1993

Licensed Content Volume 264

Licensed Content Issue 5

Type of Use Thesis/Dissertation

Requestor type author

Readers being charged a fee No

for this work 


\section{Curriculum Vitae for Alexander M. Zero}

2015-2019 BPHE, Bachelor of Physical Health and Education (with distinction)

Nipissing University

2019 - Present, MSc, School of Kinesiology University of Western Ontario

Honours, awards and scholarships: Ontario Graduate Scholarship (2020)

OUA Academic Achievement award $(2018,2019)$

U Sports Academic All-Canadian (2018, 2019)

Carl Sanders Scholarship (2016-2019)

President's Entrance Scholarship (2015)

University Athletic Scholarship (2015-2019)

Undergraduate course guest lecture:

Zero A.M. Aging and the Neuromuscular System (2021), Kinesiology 4457B

Teaching Assistant

2021/01 - 2021/05 Kinesiology 4457B - Ergonomics and Aging

2020/09 - 2020/12 Kinesiology 4430F - Neuromuscular Physiology

2020/01 - 2020/05 Kinesiology 2230B - Introductory Exercise Physiology

2019/09 - 2019/12 Kinesiology 2230A - Introductory Exercise Physiology

Publications

Zero A.M \& Rice C.L (2021) State-of-the-art review: spinal and supraspinal responses to muscle potentiation in humans. European Journal of Applied Physiology. 1-12.

DOI: $10.1007 / \mathrm{s} 00421-021-04610-\mathrm{x}$

Hali K, Zero A.M, \& Rice C.L (2021) Effect of ankle joint position on triceps surae contractile properties and motor unit discharge rates. Physiological Reports. 8(24) 1-10.

DOI: $10.14814 /$ phys 2.14680

Zero A.M, Kirk E.A, Hali K, \& Rice C.L (2021) Firing rate trajectories of human motor units during 10, 25 and 50\% isometric ramp contractions. (Submitted to Neuroscience Letters)

Zero A.M \& Rice C.L (2021) Post-activation potentiation induced by concentric contractions at three speeds in humans. (Submitted to Experimental Physiology)

\section{Conference presentations}

Zero A.M, Kirk E.A, Hali K, \& Rice C.L (2021) Firing rate trajectories of human motor units during isometric ramp contractions. Society for Neuroscience Global Connectcome (poster presentation) January 11-13, Virtual, 2021. 
Hali K, Zero A.M, Fanous J, \& Rice C.L (2020) Effect of ankle joint position on triceps surae motor unit firing rates. Federation of American Societies for Experimental Biology (FASEB), Volume 34, 2020. Experimental Biology (S1) (poster presentation)

Zero A.M \& Rice C.L (2020) Doublet discharge occurrence during muscle potentiation and its relation to neuromuscular efficiency. Health and Rehabilitation Science Conference (oral presentation) February 4, London Ontario Canada, 2020.

Zero A.M \& Rice C.L (2020) Motor unit saturation during post-activation potentiation in humans. Neuroscience Research Day (poster presentation) February 20, London Ontario Canada, 2020 .

Zero A.M, Mady C, \& Hartley G.L (2019) The impact of low-load strength training with blood flow restriction or hypoxia on Wingate performance. Exercise Neuroscience (ENG) June 17-18, Hamilton Ontario Canada, 2019. 